\title{
Recent updates on different methods of pretreatment of lignocellulosic feedstocks: a review
}

\author{
Adepu Kiran Kumar ${ }^{*}$ and Shaishav Sharma
}

\begin{abstract}
Lignocellulosic feedstock materials are the most abundant renewable bioresource material available on earth. It is primarily composed of cellulose, hemicellulose, and lignin, which are strongly associated with each other. Pretreatment processes are mainly involved in effective separation of these complex interlinked fractions and increase the accessibility of each individual component, thereby becoming an essential step in a broad range of applications particularly for biomass valorization. However, a major hurdle is the removal of sturdy and rugged lignin component which is highly resistant to solubilization and is also a major inhibitor for hydrolysis of cellulose and hemicellulose. Moreover, other factors such as lignin content, crystalline, and rigid nature of cellulose, production of post-pretreatment inhibitory products and size of feed stock particle limit the digestibility of lignocellulosic biomass. This has led to extensive research in the development of various pretreatment processes. The major pretreatment methods include physical, chemical, and biological approaches. The selection of pretreatment process depends exclusively on the application. As compared to the conventional single pretreatment process, integrated processes combining two or more pretreatment techniques is beneficial in reducing the number of process operational steps besides minimizing the production of undesirable inhibitors. However, an extensive research is still required for the development of new and more efficient pretreatment processes for lignocellulosic feedstocks yielding promising results.
\end{abstract}

Keywords: Pretreatment, Lignocellulosic biomass, Cellulose, Lignin, Reducing sugars

\section{Background}

Lignocellulosic feedstock represents an extraordinarily large amount of renewable bioresource available in surplus on earth and is a suitable raw material for vast number of applications for human sustainability. The main composition of lignocellulosic feedstocks is cellulose, hemicellulose, and lignin (Table 1). However, many obstacles are associated with effective utilization of lignocellulosic materials. Some of the major factors are the recalcitrance of the plant cell wall due to integral structural complexity of lignocellulosic fractions and strong hindrance from the inhibitors and byproducts that are generated during pretreatment. In addition, few more challenges still remain, like understanding the

*Correspondence: kiranbio@gmail.com

Bioconversion Technology Division, Sardar Patel Renewable Energy Research Institute, Vallabh Vidyanagar, Anand 388 120, Gujarat, India physicochemical architecture of feedstock cell walls, suitable pretreatment method and extent of cell wall deconstruction for generation of value-added products etc.

There are several criteria for the selection of a suitable pretreatment method: (a) the selected method should avoid the size reduction of biomass particles, (b) hemicellulose fraction must be preserved, (c) minimize the formation of degradation products, (d) minimize the energy demands and lastly, (e) should involve a low-cost pretreatment catalyst and/or inexpensive catalyst recycle and regeneration of high-value lignin co-product (Wyman 1999). The result of the pretreatment must not only defend but also justify its impact on the cost of downstream processing steps and the tradeoff between operating costs, capital costs, biomass costs, etc. (Lynd et al. 1996).

The pretreatment techniques for overcoming biomass recalcitrance are broadly divided into two classes: 
Table 1 Cellulose, hemicellulose, and lignin content in common lignocellulosic feedstocks

\begin{tabular}{llll}
\hline $\begin{array}{l}\text { Lignocellulosic } \\
\text { feedstocks }\end{array}$ & Cellulose (\%) & Hemicellulose (\%) & Lignin (\%) \\
\hline Sugar cane bagasse & 42 & 25 & 20 \\
Sweet sorghum & 45 & 27 & 21 \\
Hardwood & $40-55$ & $24-40$ & $18-25$ \\
Softwood & $45-50$ & $25-35$ & $25-35$ \\
Corn cobs & 45 & 35 & 15 \\
Corn stover & 38 & 26 & 19 \\
Rice Straw & 32 & 24 & 18 \\
Nut shells & $25-30$ & $25-30$ & $30-40$ \\
Newspaper & $40-55$ & $25-40$ & $18-30$ \\
Grasses & $25-40$ & $25-50$ & $10-30$ \\
Wheat straw & $29-35$ & $26-32$ & $16-21$ \\
Banana waste & 13.2 & 14.8 & 14 \\
Bagasse & 54.87 & 16.52 & 23.33 \\
Sponge gourd fibers & 66.59 & 17.44 & 15.46 \\
Agricultural residues & $5-15$ & $37-50$ & $25-50$ \\
Hardwood & $20-25$ & $45-47$ & $25-40$ \\
Softwood & $30-60$ & $40-45$ & $25-29$ \\
Grasses & 0 & $25-40$ & $35-50$ \\
Waste papers from & $6-10$ & $50-70$ & $12-20$ \\
chemical pulps & & & $25-40$ \\
Newspaper & 12 & $40-55$ & 0 \\
Sorted refuse & 60 & 20 & 12 \\
Leaves & $15-20$ & $80-85$ & $0-15$ \\
Cotton seed hairs & $80-95$ & $5-20$ & 0 \\
Paper & $85-99$ & 0 & \\
Switch grass & 45 & 31.4 & \\
\hline & & & \\
\hline
\end{tabular}

biochemical and thermochemical (Laser et al. 2009). Based on the operating temperatures, thermochemical pretreatment is again of two types: pyrolysis and gasification. The advantage of thermochemical conversion is that it is a fast process with low residence time and is able to handle a broad range of feedstock in a continuous manner, but major drawback is its non-specific nature of biomass deconstruction. On the other hand, biochemical pretreatment is highly selective in biomass deconstruction to their desired product formation. However, biochemical conversion first uses low-severity thermochemical pretreatment to partially break down the cell wall and expose the cellulose and hemicellulose fractions for improving enzyme accessibility. Elucidating the physicochemical effects of the possible pretreatments upon subsequent hydrolysis and fermentation of biomass has been a significant challenge.

Although several reviews have been present which describe the various categories of pretreatment processes individually, however, a comprehensive review covering different types of pretreatment processes along with their advantages and disadvantages was the need of the hour. Therefore, this review covers all the techniques that have been developed and used for pretreatment of lignocellulosic biomass, recent advancements in pretreatment technology, their mechanism of action, and effect on various lignocellulosic feedstocks.

\section{Methods of pretreatment}

The pretreatment of lignocellulosic feedstocks is an essential step and is required to alter the structure of biomass residues and expose the lignocellulosic fractions for easy access to enzymes during enzymatic hydrolysis and enhance the rate and yield of reducing sugars (Alvira et al. 2010). Basically, the pretreatment processes are classified into two major regimes viz. non-biological and biological. A list of promising and most commonly used pretreatment methods are listed in Fig. 1. Based on the type of the treatment process involved, lignocellulosic biomass pretreatment methods are broadly classified into two groups: Non-biological and biological. Non-biological pretreatment methods do not involve any microbial treatments and are roughly divided into different categories: physical, chemical, and physico-chemical methods. Here, we have reviewed the advances in few selective treatment methods that are most commonly employed in pretreatment process of a broad range of lignocellulosic feedstocks.

\section{Physical pretreatment Mechanical extrusion}

It is the most conventional method of biomass pretreatment where the feedstock materials are subjected to heating process $\left(>300{ }^{\circ} \mathrm{C}\right)$ under shear mixing. This pretreatment process results mainly in production of gaseous products and char from the pretreated lignocellulosic biomass residues (Shafizadeh and Bradbury 1979). Due to the combined effects of high temperatures that are maintained in the barrel and the shearing force generated by the rotating screw blades, the amorphous and crystalline cellulose matrix in the biomass residues is disrupted. However, this method requires significant amount of high energy making it a cost intensive method and difficult to scale up for industrial purposes (Zhu and Pan 2010). Karunanithy et al. (2008) studied on the defibrillation and shortening of the biomass fibers and concomitant increase in the overall content of the carbohydrates and its availability for enzymatic hydrolysis process.

Zheng and Rehmann (2014) studied different process parameters of mechanical extraction process and found that the type of the screw design, compression ratio, screw speed, and barrel temperature affected the biomass pretreatment. Similarly, Karunanithy and Muthukumarappan (2010) also studied the effect of temperature 


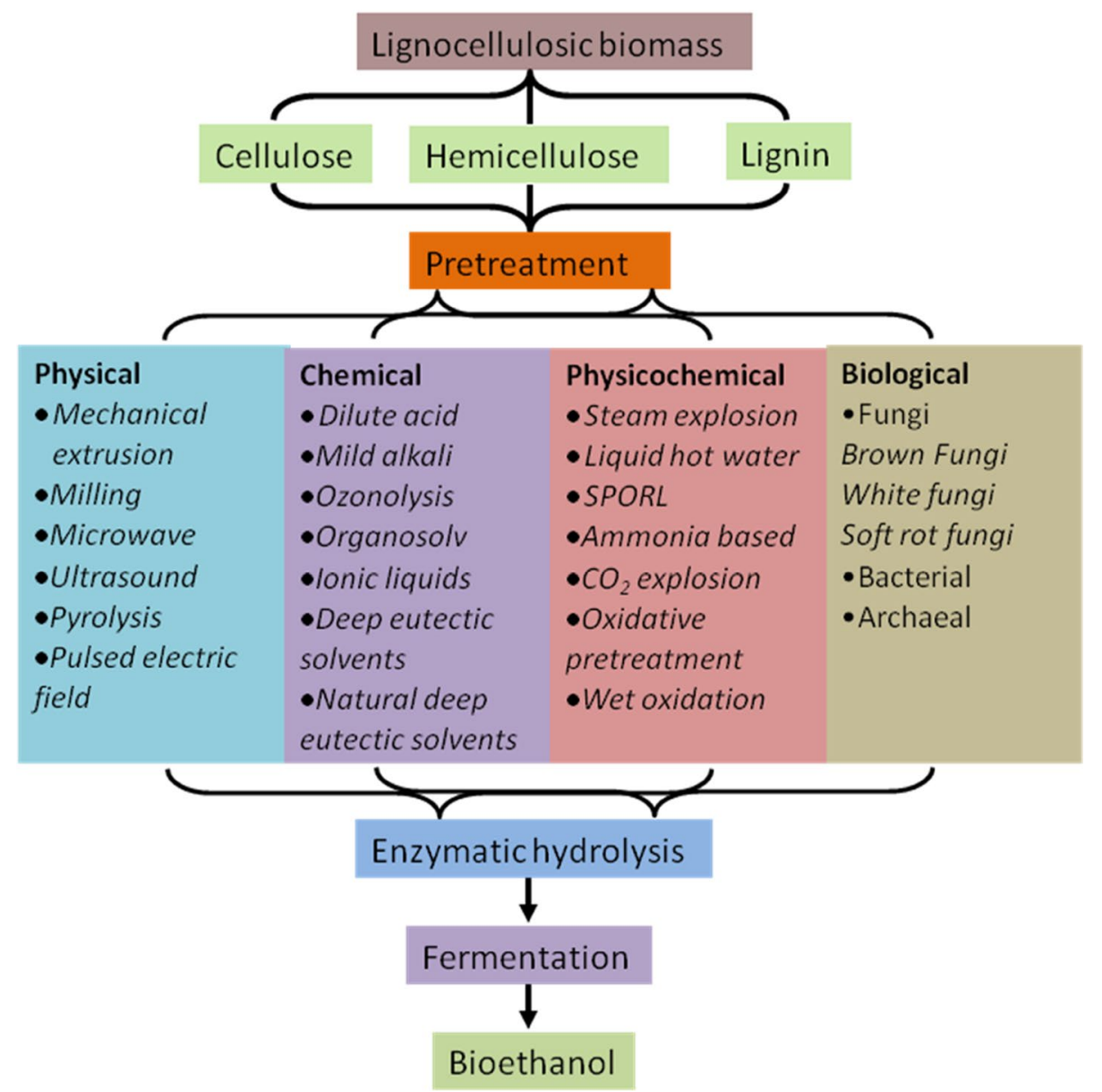

Fig. 1 Overview of different pretreatment processes

and screw speed on pretreatment of corn cobs with different cellulose degrading enzymes and their ratios. When pretreatment was carried out at different temperatures $\left(25,50,75,100\right.$, and $\left.125^{\circ} \mathrm{C}\right)$ and different screw speeds ( $25,50,75,100$, and $125 \mathrm{rpm})$, maximum concentrations of glucose $(75 \%)$, xylose $(49 \%)$, and combined sugars $(61 \%)$ were obtained at $75 \mathrm{rpm}$ and $125^{\circ} \mathrm{C}$ using cellulase and $\beta$-glucosidase in the ratio of $1: 4$, which were nearly 2.0, 1.7, and 2.0 times higher than the controls. These clearly indicated that optimization of the pretreatment process conditions and enzyme concentrations had a synergetic effect on the overall yields of reducing sugars.

Moreover, in another study, Karunanithy et al. (2013) selected different varieties of warm season grasses viz. switch grass, big bluestem, and prairie cord grass and studied the effect of different screw speeds $(100,150$, and $200 \mathrm{rpm}$ ), barrel temperatures (50, 75, 100, 150, and $200{ }^{\circ} \mathrm{C}$ ) and different concentrations of cellulase with $\beta$-glucosidase (1:1 to $1: 4)$. In all the experiments, maximum reducing sugars were obtained when the ratio of cellulase and $\beta$-glucosidase was maintained at 1:4. The reducing sugar yields from the switchgrass pretreated at screw speed of $200 \mathrm{rpm}$ and barrel temperature of $75{ }^{\circ} \mathrm{C}$ produced $28.2 \%$, while big bluestem pretreated at screw speed of $200 \mathrm{rpm}$ and $150{ }^{\circ} \mathrm{C}$ barrel temperature produced $66.2 \%$ and with prairie cord grass pretreated at $150 \mathrm{rpm}$ and $100{ }^{\circ} \mathrm{C}$ produced $49.2 \%$. Although the sugar yields are high, mechanical extrusion cannot alone suffice pretreatment of a range of lignocellulosic feedstocks with varied cellulose, hemicellulose, and lignin contents. Thus, it needs better pretreatment methods for higher sugar yields. Besides, sugar recovery is also significantly influenced by the properties of the biomass.

Karunanithy and Muthukumarappan (2010) studied the effect of varying moisture contents $(15,25,35$, and $45 \%$ $\mathrm{wb})$ on the sugar recovery from switch grass and prairie cord grass at compression ratio (2:1 and 3:1), screw speed (50, 100 and $150 \mathrm{rpm})$, and barrel temperature $(50,100$, and $150{ }^{\circ} \mathrm{C}$ ). After enzymatic hydrolysis of the pretreated 
biomass, maximum $45.2 \%$ sugar was recovered from switch grass with $15 \%$ moisture content at screw speed of $50 \mathrm{rpm}$ and barrel temperature of $150{ }^{\circ} \mathrm{C}$, whereas a maximum of $65.8 \%$ sugar was recovered from prairie cord grass with $25 \%$ moisture content at screw speed of $50 \mathrm{rpm}$ and barrel temperature of $50{ }^{\circ} \mathrm{C}$. Alongside, low concentrations of glycerol and acetic acid in the range of $0.02-0.18 \mathrm{~g} / \mathrm{L}$ were also produced. It is well known that glycerol and acetic acid are the byproducts that are formed during the pretreatment of lignocellulosic feedstocks. However, in this report, unlike hot compressed hot water and acid hydrolysis, the byproduct formation was significantly lower because in mechanical extraction only physical interactions were observed between the feedstock and the barrel blades. Similarly, Lamsal et al. (2010) also compared effects of grinding with extrusion on wheat bran and soybean hull. Better sugar yield was obtained in wheat bran through extrusion but not in soybean hulls. The most plausible reason could be due to the difference in the lignin contents between these biomass residues. Soybean hulls contain nearly twofold higher lignin content than the wheat bran. The residual high-lignin bound to the pretreated biomass could have shown a direct impact on the enzymatic hydrolysis. It is well known that the cellulose degrading enzymes avidly and irreversibly bind to lignin and thus not readily available for effective cellulose disruption. The combination of screw speed and barrel temperature maintained was $7 \mathrm{~Hz} / 150{ }^{\circ} \mathrm{C}$ and $3.7 \mathrm{~Hz} / 110{ }^{\circ} \mathrm{C}$ where highest sugar yield was produced.

Moreover, particle size of biomass plays an important role on the overall sugar recovery. Studies performed by Karunanithy and Muthukumarappan (2011) showed maximum sugar recovery from big blue stem obtained with $8-\mathrm{mm}$ particle size, $20 \%$ wb moisture content at a barrel temperature of $180{ }^{\circ} \mathrm{C}$ with screw speed of $150 \mathrm{rpm}$, where $71.3 \%$ glucose, $78.5 \%$ xylose, and $56.9 \%$ combined sugars were obtained. While with switch grass, at similar particle size and moisture contents, but at a barrel temperature of $176^{\circ} \mathrm{C}$ and screw speed of $155 \mathrm{rpm}$, maximum sugars of $41.4 \%$ glucose, $62.2 \%$ xylose, and $47.4 \%$ combined sugars were obtained. In another study, Zhang et al. (2012a, b) used a twin screw extruder for sugar recovery from corn stover. At 27.5\% moisture content with a screw speed of $80 \mathrm{rpm}$ and enzyme dose of $0.028 \mathrm{~g}$ enzyme/g dry biomass, glucose, xylose, and combined sugar recovery were $48.79,24.98$, and $40.07 \%$, respectively. These were $2.2,6.6$, and 2.6 times more than that of untreated corn stover. Yoo (2011) compared a thermo-mechanical pretreatment process on soybean hulls. Under optimum processing conditions at screw speed of $350 \mathrm{rpm}$, barrel temperature of $80{ }^{\circ} \mathrm{C}$ and $40 \%$ moisture content, $95 \%$ cellulose was converted glucose.
These above studies clearly demonstrate that mechanical extrusion treatment had a significant effect on breakdown of cellulose and hemicelluloses fractions from a wide variety of lignocellulosic feedstocks; however, when combined with other pretreatment methods, mechanical extrusion performs better and might enhance the overall yields of the reducing sugars.

\section{Milling}

Mechanical grinding (milling) is used for reducing the crystallinity of cellulose. It mostly includes chipping, grinding, and/or milling techniques. Chipping can reduce the biomass size to $10-30 \mathrm{~mm}$ only while grinding and milling can reduce the particle size up to $0.2 \mathrm{~mm}$. However, studies found that further reduction of biomass particle below $0.4 \mathrm{~mm}$ has no significant effect on rate and yield of hydrolysis (Chang et al. 1997). Chipping reduces the heat and mass transfer limitations while grinding and milling effectively reduce the particle size and cellulose crystallinity due to the shear forces generated during milling. The type and duration of milling and also the kind of biomass determine the increase in specific surface area, final degree of polymerization, and the net reduction in cellulose crystallinity. Different milling methods viz. two-roll milling, hammer milling, colloid milling, and vibratory milling are used to improve the digestibility of the lignocellulosic materials (Taherzadeh and Karimi 2008). Compared to ordinary milling process, vibratory ball milling is found to be more effective in reducing cellulose crystallinity and improving the digestibility of spruce and aspen chips. Also, wet disk milling has been a popular mechanical pretreatment because of its low energy consumption. Disk milling enhances cellulose hydrolysis by producing fibers and is more effective as compared to hammer milling which produces finer bundles (Zhua et al. 2009). Hideno et al. (2009) compared the effect of wet disk milling and conventional ball milling pretreatment method over rice straw. The optimal conditions obtained were $60 \mathrm{~min}$ of milling in case of dry ball milling while 10 repeated milling operations were required in case of wet disk milling. Maximum glucose $(89.4 \%)$ and xylose (54.3\%) were obtained with conventional ball milling method as compared to $78.5 \%$ glucose and $41.5 \%$ xylose with wet disk milling method. However, wet disk milling had lower energy requirement, high effectiveness for enzymatic hydrolysis, and did not produce inhibitors. Lin et al. (2010) found wet milling better than dry milling for the pretreatment of corn stover. The optimum parameters for milling were particle size $0.5 \mathrm{~mm}$, solid/liquid ratio of 1:10, 20 number of steel balls of $10 \mathrm{~mm}$ dia each, ball speed of $350 \mathrm{rpm} /$ min grounded for $30 \mathrm{~min}$. Better results were obtained when milling was combined with alkaline pretreatment 
method. As compared to wet milling process, alkaline milling treatment increased the enzymatic hydrolysis efficiency of corn stover by $110 \%$. Sant Ana da Silva et al. (2010) performed a comparative analysis on effects of ball milling and wet disk milling on treating sugarcane bagasse and straw and found ball milling better pretreatment method than wet disk milling in terms of glucose and xylose hydrolysis yields. Ball milling-treated bagasse and straw produced 78.7 and 72.1 and 77.6 and 56.8\%, glucose and xylose, respectively. Kim et al. (2013) compared three different milling methods i.e., ball, attrition, and planetary milling. Attrition and planetary mills were found more effective in reducing the size of biomass as compared to ball milling. Planetary mill produced highest amount of glucose and galactose than other milling methods tested. It is to be noted that all the mill pretreatment methods do not produce any toxic compounds like hydroxymethylfurfuraldehyde (HMF) and levulinic acid. This makes milling pretreatment a good choice of preliminary pretreatment method for a wide variety of lignocellulosic feed stocks. In another study, oil palm frond fiber when pretreated through ball mill produced glucose and xylose yields of 87 and $81.6 \%$, respectively, while empty fruit bunch produced glucose and xylose yields of 70 and $82.3 \%$, respectively (Zakaria et al. 2014).

\section{Microwave}

Microwave irradiation is a widely used method for lignocellulosic feedstock pretreatment because of various reasons such as (1) easy operation, (2) low energy requirement, (3) high heating capacity in short duration of time, (4) minimum generation of inhibitors, and (5) degrades structural organization of cellulose fraction. Moreover, addition of mild-alkali reagents is preferred for more effective breakdown. A study on microwavebased alkali pretreatment of switch grass yielded nearly 70-90\% sugars (Hu and Wen 2008). Microwave-based alkali treatment of switchgrass and coastal bermudagrass using different alkalis found sodium hydroxide as the most suitable alkali. Under optimum conditions, switchgrass produced $82 \%$ glucose and $63 \%$ xylose while coastal bermudagrass produced $87 \%$ glucose and 59\% xylose (Keshwani and Cheng 2010). Although not significant, the authors have correlated the differences in reducing sugars with the difference in the lignin content $(19 \%$ in bermudagrass vs $22 \%$ in switchgrass) in these lignocellulosic feedstocks. Lu et al. (2011) studied microwave pretreatment of rape straw at different powers for different time durations. The higher power of microwave resulted in higher glucose production but treatment time did not have a significant effect at a specific power setting. Chen et al. (2011a, b) optimized the microwave heating at $190{ }^{\circ} \mathrm{C}$ for $5 \mathrm{~min}$ for bagasse pretreatment in terms of lignocellulosic structural disruption. In another investigation, Zhu et al. (2015a, b, 2016) have extensively studied the effects of microwave on chemically pretreated Miscanthus. Where, microwave treatment was applied to $\mathrm{NaOH}$ - and $\mathrm{H}_{2} \mathrm{SO}_{4}$-pretreated Miscanthus and found 12-times high sugar yield in half the time as compared to conventional heating $\mathrm{NaOH}$ and $\mathrm{H}_{2} \mathrm{SO}_{4}$ pretreatment. This was mainly due to the pre-disruption of crystalline cellulose and lignin solubilization with the chemical pretreatment. The maximum sugar yield obtained was $75.3 \%$ and glucose yield was $46.7 \%$ when pretreated with $0.2 \mathrm{M}$ $\mathrm{H}_{2} \mathrm{SO}_{4}$ for $20 \mathrm{~min}$ at $180{ }^{\circ} \mathrm{C}$. Similarly, Xu et al. (2011) developed an orthogonal design to optimize the microwave pretreatment of wheat straw and increased the ethanol yield from 2.678 to $14.8 \%$. Bonmanumsin et al. (2012) reported substantial increase in yield of monomeric sugars from Miscanthus sinensis with microwaveassisted ammonium hydroxide treatment. Microwave pretreatment of oil palm empty fruit bunch fiber in the presence of alkaline conditions showed $74 \%$ reduction in lignin (Nomanbhay et al. 2013).

\section{Ultrasound}

Sonication is relatively a new technique used for the pretreatment of lignocellulosic biomass. However, studies in the laboratory have found sonication a feasible pretreatment option. Ultrasound waves produce both physical and chemical effects which alter the morphology of lignocellulosic biomass. Ultrasound treatment leads to formation of small cavitation bubbles which rupture the cellulose and hemicellulose fractions thereby increasing the accessibility to cellulose degrading enzymes for effective breakdown into simpler reducing sugars. Yachmenev et al. (2009) reported that the maximum cavitation was formed at $50{ }^{\circ} \mathrm{C}$ which is also the optimum temperature for many cellulose degrading enzymes. The ultrasonic field is primarily influenced by ultrasonic frequency and duration, reactor geometry and its type and solvent used. Furthermore, biomass characteristics, reactor configuration, and kinetics also influence the pretreatment through sonication (Bussemaker and Zhang 2013). Duration of sonication has maximum effect on pretreatment of biomass. However, prolonging sonication beyond a certain limit has no additional effect in terms of delignification and sugar release (Rehman et al. 2013). Sonication of corn starch slurry for $40 \mathrm{~s}$ increased the sugar yield by 5-6 times as compared to control (Montalbo et al. 2010). Sonication of alkaline pretreated wheat straw for $15-35$ min increased delignification by $7.6-8.4 \%$ as compared to control (Sun and Tomkinson 2002). Besides duration, the frequency of sonication directly determines the power of sonication, which is also an important factor affecting the lignocellulosic feedstock pretreatment. 
Most of the researchers have used ultrasound frequency of $10-100 \mathrm{kHz}$ for the pretreatment process which has been enough for cell breakage and polymer degradation (Gogate et al. 2011). However, higher sonication power level is reported to adversely affect the pretreatment process. High power leads to formation of bubbles near tip of ultrasound transducer which hinders the transfer of energy to the liquid medium (Gogate et al. 2011). Increased oxidation of cellulose has been observed in when the sonication power was increased to $400 \mathrm{~W}$ in $200 \mathrm{~mL}$ of slurry (Aimin et al. 2005). Similarly, poplar wood cellulose powder suspension turned viscous when treated with high power of $1200 \mathrm{~W}$ sonication (Chen et al. 2011a, b). Therefore, power and duration of sonication should be optimized based on the biomass and slurry characteristics to meet the desired pretreatment objectives.

\section{Pyrolysis}

Pyrolysis has also been employed for the pretreatment of lignocellulosic biomass, however, in biorefinery processes. Unlike bioethanol applications, pyrolysis treatment is used for production of bio-oil from lignocellulosic feedstocks. Although limited studies have been reported on use of pyrolysis for reducing sugars production, there are few reports on use of pyrolysis in pretreatment of chemically pretreated biomass. Hence, we have included a brief section on pyrolysis pretreatment in this review. Fan et al. (1987) applied mild acid hydrolysis $\left(1 \mathrm{~N}\right.$ sulfuric acid, at $97^{\circ} \mathrm{C}$ for $\left.2.5 \mathrm{~h}\right)$ on the pyrolysis-pretreated biomass and found $\sim 85 \%$ conversion of cellulose to reducing sugars and $>5 \%$ glucose. In brief, pyrolysis is a thermal degradation process where biomass was subjected to high-temperature treatment, generally operated at $500-800{ }^{\circ} \mathrm{C}$ in the absence of oxidizing agent. At this temperature, cellulose rapidly decomposes leading to formation of end products such as gaseous substances, pyrolysis oil, and charcoal (Kilzer and Broido 1965). Pyrolysis is divided into slow and fast pyrolysis based on the heating rate. The amount of each end product varies depending on the type of pyrolysis, biomass characteristics, and reaction parameters. Besides production of high value energy-rich products, pyrolysis is adapted by thermal industries due to easy transport management, storage, combustion, and retrofitting and is flexible in production and marketing. Pyrolysis is found to be more efficient when carried out in the presence of oxygen at lower temperatures (Shafizadeh and Bradbury 1979; Kumar et al. 2009). Shafizadeh and Bradbury carried out the pyrolysis in the presence of oxygen as well as nitrogen and found that a large number of bonds were broken in the presence of oxygen as compared to nitrogen. It was estimated that at
$25{ }^{\circ} \mathrm{C}, 7.8 \times 10^{9}$ bonds $/ \mathrm{min} / \mathrm{g}$ cellulose is cleaved in the presence of oxygen as compared to $1.7 \times 10^{8}$ bonds with nitrogen under similar conditions.

Biomass to liquid (BtL) route is used for the production of transportation of fuels from biomass which includes conversion of biomass to syngas to high-quality Fischer-Tropsch (FT) fuels. Zwart et al. (2006) compared alternative BtL routes comprising chipping, torrefaction, pelletization, and pyrolysis. The most efficient and commercially feasible route was found to be based on torrefaction followed by pyrolysis and pelletization. The study also clearly demonstrated the advantage of pretreatment at the front end of BtL production route by decreasing the cost of FT product by $\sim 3$ Euro/GJ.

\section{Pulsed-electric field}

Pulsed-electric field (PEF) pretreatment exposes the cellulose present in the biomass by creating the pores in the cell membrane thereby allowing the entry of agents that will break the cellulose into constituent sugars. In PEF pretreatment, the biomass is subjected to a sudden burst of high voltage between $5.0-20.0 \mathrm{kV} / \mathrm{cm}$ for short durations (nano to milliseconds). The advantages of PEF are low energy requirement due to very short duration $(100 \mu \mathrm{s})$ of pulse time and the treatment can be carried out at ambient conditions. Also, the PEF instrument is simple in design due to lack of moving parts (Kumar et al. 2009). Salerno et al. (2009) applied PEF to waste activated sludge and pig manure for increasing the production of methane during anaerobic digestion. Methane production increased twofold from sludge and $80 \%$ from pig manure as compared to untreated sludge and manure. Kumar et al. (2011) designed and developed a PEF system for the pretreatment of wood chip and switchgrass. They studied the effect of PEF on untreated and treated samples through the uptake of neutral red dye. Both switch grass and woodchip were found resistant to structural change at low field strengths. Switchgrass showed higher neutral red uptake at field strength $\geq 8 \mathrm{kV} / \mathrm{cm}$ while woodchip showed similar results at $10 \mathrm{kV} / \mathrm{cm}$. Electric field strength and pulse duration are the two interdependent processing parameters affecting electroporation through PEF. Two different durations in the range of milliseconds and microseconds were applied to Chlorella vulgaris and found irreversible electroporation at $>4 \mathrm{kV} /$ $\mathrm{cm}$ in the millisecond range and at $\geq 10 \mathrm{kV} / \mathrm{cm}$ in the microseconds range (Luengo et al. 2015). Yu et al. (2016) optimized pressure, electric field strength, and pulse number on the juice expression yield, total polyphenols, and total proteins content in the expressed juices of rapeseed stem biomass. The optimum conditions of electric field strength $E=8 \mathrm{kV} / \mathrm{cm}$, pressure $P=10$ bar and pulse number $\mathrm{tPEF}=2 \mathrm{~ms}$ increased juice yield from 
34 to $81 \%$. Total polyphenols and total proteins content increased significantly after PEF pretreatment.

\section{Chemical pretreatment Dilute acid}

Although acid treatment is the most commonly used conventional pretreatment method of lignocellulosic feedstocks, it is less attractive due to the generation of high amount of inhibitory products such as furfurals, 5-hydroxymethylfurfural, phenolic acids, and aldehydes. The corrosive and toxic nature of most acids requires a suitable material for building the reactor which can sustain the required experimental conditions and corrosive nature of acids (Saha et al. 2005). Still it is the most widely employed pretreatment method on industrial scale. Based on the type of end application, two types of acid pretreatments are developed; high temperature (above $180^{\circ} \mathrm{C}$ ) for short duration (1-5 min) and low temperature $\left(<120^{\circ} \mathrm{C}\right)$ for long duration (30-90 $\mathrm{min})$, respectively. In some cases, enzymatic hydrolysis step could easily be avoided as acid itself hydrolyses the biomass into fermentable sugars. However, extensive washing is necessary to remove acid before fermentation of sugars (Sassner et al. 2008). Different types of reactors such as percolation, plug flow, shrinking-bed, batch, flow-through, and counter current reactors have been developed. However acid treatment generates inhibitors which need to be removed before further processing. Also, the concentrated acid must be recovered after hydrolysis in order to make the process economically feasible. Different acids have been used for the pretreatment of a variety of biomass. Some of the commonly used acids are discussed here:

Sulfuric acid The most common commercially used acid is dilute sulphuric acid $\left(\mathrm{H}_{2} \mathrm{SO}_{4}\right)$. It has been widely used to pretreat switchgrass (Digman et al. 2010), corn stover (Xu et al. 2009), spruce (Shuai et al. 2010), and poplar (Kumar and Wyman 2009). Pretreatment of bermuda grass and rye straw with $1.5 \%$ sulphuric acid followed by enzymatic hydrolysis yielded 19.71 and $22.93 \%$ reducing sugars from bermuda grass and rye straw, respectively (Sun and Cheng 2005). Kim et al. (2011a, b) carried pretreatment of rice straw in two-stage process using aqueous ammonia and dilute $\mathrm{H}_{2} \mathrm{SO}_{4}$ in percolation mode. The yield of reducing sugars was observed to be 96.9 and $90.8 \%$, respectively, indicating that combination of these two processes resulted in better removal of lignin and hemicelluloses. Pretreatment liquor of Eulaliopsis binata (a perennial grass commonly found in India and China) with diluted $\mathrm{H}_{2} \mathrm{SO}_{4}$ at optimum conditions resulted in $21.02 \%$ total sugars, $3.22 \%$ lignin, and $3.34 \%$ acetic acid with the generation of low levels of inhibitors (Tang et al.
2013). Acid pretreatment of wheat and rice straw gave maximum sugar yield of 565 and $287 \mathrm{mg} / \mathrm{g}$, respectively, with no furfural and hydroxymethyl furfural formation (Saha et al. 2005).

Due to its low cost, pretreatment of lignocellulosic biomass through sulfuric acid is a conventional method. However, it has certain disadvantages such as production of inhibitory compounds and corrosion of reaction vessel (Lee and Jeffries 2011). Therefore researchers have carried out the pretreatment of lignocellulosic biomass through various other acids such as oxalic acid and maleic acid which are discussed later in the review (Kootstra et al. 2009; Lu and Mosier 2007; Lee et al. 2009).

Dicarboxylic acids: oxalic and maleic acid As described earlier, other class of acids called as dicarboxylic acids are being tested by researchers in order to overcome the drawbacks associated with sulfuric acid. Such acids have higher $\mathrm{pKa}$ values than sulfuric acid and therefore have a higher solution $\mathrm{pH}$ as compared to sulfuric acid which is a type of mineral acid. Dicarboxylic organic acids exhibit two pKa values which make them more efficient for carrying out the hydrolysis of the substrate over a range of temperature and $\mathrm{pH}$ values (Lee and Jeffries 2011).

Apart from above mentioned advantages, oxalic acid is less toxic to yeasts and other microorganisms than sulfuric and acetic acids, does not hamper glycolysis and does not produce odor. Lee and coworkers (2011) used oxalic acid for the pretreatment of corn cobs. Corn cob was heated to $168{ }^{\circ} \mathrm{C}$ and kept for $26 \mathrm{~min}$. A total sugar yield of $13 \%$ was obtained through oxalic acid pretreatment. Also, it produced very less amount of inhibitors.

Maleic acid is another common dicarboxylic acid used for the pretreatment purpose. Along with the advantages mentioned above, maleic acid in particular has $k_{h y d} / k_{\text {deg }}$ which favors cellulose hydrolysis to glucose over glucose degradation (Mosier et al. 2002). Lee and Jeffries (2011) investigated the effects of oxalic, maleic, and sulfuric acid on hydrolysis and degradation of lignocellulosic biomass at same combined severity factor (CSF) during hydrolysis. At low CSF values, xylose and glucose concentrations were found to be highest in maleic acid followed by oxalic acid and sulfuric acid. The subsequent fermentation with pretreated biomass yielded maximum ethanol (19.2 g/L) at CSF 1.9 when maleic acid was used for pretreatment of biomass.

Marzialetti et al. (2008) studied the effect of different acids viz. TFA, $\mathrm{HCl}, \mathrm{H}_{2} \mathrm{SO}_{4}, \mathrm{HNO}_{3}$, and $\mathrm{H}_{3} \mathrm{PO}_{4}$ on loblolly pine in a batch reactor. TFA yielded highest amount of soluble monosaccharides at $150{ }^{\circ} \mathrm{C}$ and $\mathrm{pH}$ 1.65 . 


\section{Mild-alkali}

In contrary to acid treatment, alkali pretreatment methods are in general performed at ambient temperature and pressure. The most commonly used alkali reagents are the hydroxyl derivatives of sodium, potassium, calcium, and ammonium salts. Among these hydroxyl derivatives, sodium hydroxide was found to be most effective (Kumar and Wyman 2009). Alkali reagents degrade the side chains of esters and glycosides leading to structural modification of lignin, cellulose swelling, cellulose decrystallization, and hemicellulose solvation (Cheng et al. 2010; Ibrahim et al. 2011; McIntosh and Vancov 2010; Sills and Gossett 2011). Sun et al. (1995) optimized the concentration, temperature, and duration of pretreatment using sodium hydroxide. The optimized condition was $1.5 \%$ sodium hydroxide at $20{ }^{\circ} \mathrm{C}$ for $144 \mathrm{~h}$ released $60 \%$ lignin and $80 \%$ hemicellulose. Zhao et al. (2008) showed the effect of sodium hydroxide on different biomass viz. wheat straw, hardwoods, switchgrass, and softwoods containing less than $26 \%$ lignin. However, no effect of dilute $\mathrm{NaOH}$ was observed on softwoods with lignin content greater than 26\% (Kumar and Wyman 2009). As compared to untreated cellulose, the sodium hydroxide treated corn stover showed increase in biogas production by $37 \%$ (Zhu et al. 2010). As compared to acid pretreatment, the solubility of cellulose and hemicellulose is very low with the alkali pretreatment. The solubility improves on increasing the internal surface area of cellulose, decreasing the degree of polymerization and crystallinity, and disrupting the lignin structure (Taherzadeh and Karimi 2008). The conditions for mild alkali pretreatment are less harsh as compared to other pretreatment methods especially acid pretreatment method. Mild alkali pretreatment can be successfully carried out at ambient conditions, however, higher temperature are required if the pretreatment is needed to be carried out for longer duration. Further, a neutralizing step is required to remove the inhibitors as well as lignin (Brodeur et al. 2011). The benefit of lime pretreatment is the low cost of lime as compared to other alkaline agents. For example, in 2005 , cost of hydrated lime was $\$ 70 /$ ton as compared to $\$ 270 /$ ton ammonia and $\$ 320 /$ ton for $50 \mathrm{wt} \%$ $\mathrm{NaOH}$ and $45 \mathrm{wt} \% \mathrm{KOH}$ (Brodeur et al. 2011). Also, it can be easily recovered from hydrolysate by reaction with $\mathrm{CO}_{2}$. Park et al. (2010a, b) modified the lime pretreatment method by neutralizing the lime with carbon dioxide before hydrolysis. This eliminated the solid-liquid separation step resulting in $89 \%$ glucose recovery from leafstar rice straw. They also applied this modification to examine simultaneous saccharification and fermentation (SSF) by using Saccharomyces cerevisae and Pichia stipitis which found $74 \%$ increase in ethanol yield after $79 \mathrm{~h}$ of fermentation at $30{ }^{\circ} \mathrm{C}$. Being an inexpensive pretreatment method, the only drawback of alkali treatment is its high downstream processing cost because the process utilizes a large quantity of water for removing the salts from the biomass and is a cumbersome process to remove them.

\section{Ozonolysis}

Ozone treatment is mainly used for reducing the lignin content of lignocellulosic biomass as it mainly degrades lignin but negligibly affects hemicellulose and cellulose (Kumar et al. 2009). It has been used for removal of lignin in various biomass such as wheat straw (Ben and Miron 1981), bagasse, green hay, peanut, pine (Neely 1984) and poplar sawdust (Vidal and Molinier 1988). A laboratory scale ozonolysis setup was designed and developed by Vidal and Molinier for the pretreatment of different biomass. The pretreatment of wheat straw in the mentioned reactor resulted in $60 \%$ removal of lignin followed by fivefold increase in enzymatic hydrolysis. In case of poplar sawdust, lignin percentage was reduced to $8 \%$ and sugar yield increased to $57 \%$ (Vidal and Molinier 1988). Unlike other chemical pretreatment methods, ozonolysis is performed at ambient temperature and pressure. Also, it does not produce any toxic inhibitors therefore is environment friendly and does not affect the post-pretreatment processes like enzymatic hydrolysis and yeast fermentations (Quesada et al. 1999). The important factor which affects the ozone pretreatment is the moisture content of the biomass, higher the moisture content, lower the lignin oxidization. Although ozonolysis is an effective pretreatment method, the high amount of ozone required makes it an expensive pretreatment method, making it a less suitable option for pretreatment at industrial scale. In order to make an economically viable pretreatment method, research is in progress in different areas such as generation of industrially feasible ozone concentrations, development of reactors such as packed bed, fixed-bed, and stirred tank semi-batch reactors that are capable of accommodating large quantities of lowmoisture $(<30 \%)$ biomass residues having particle size between 1 and $200 \mathrm{~mm}$.

\section{Organosolv}

This process involves addition of aqueous organic solvents such as ethanol, methanol, ethylene glycol, acetone etc. to the biomass under specific condition of temperature and pressure (Alriols et al. 2009; Ichwan and Son 2011). Commonly, this process takes place in the presence of an acid, base or salt catalyst (Bajpai 2016). Temperature in organosolv pretreatment depends on the type of biomass and catalyst involved and may reach up to $200{ }^{\circ} \mathrm{C}$. This process is mainly used for the extraction of lignin which is a value-added product. Apart from lignin, cellulose fraction and hemicellulose syrup of C5 and C6 
sugars are also produced during the course of organosolv pretreatment. Removal of lignin from the biomass exposes the cellulose fibers for enzymatic hydrolysis leading to higher conversion of biomass (Agbor et al. 2011). The physical characteristics of pretreated biomass such as fiber length, degree of cellulose polymerization, crystallinity etc. depends upon variable factors such as temperature, reaction time, solvent concentration and catalyst used. High temperatures, high acid concentrations, and long reaction time have led to the formation of inhibitors of fermentation. Park et al. (2010a, b) studied the effect of different catalysts $\left(\mathrm{H}_{2} \mathrm{SO}_{4}, \mathrm{NaOH}\right.$, and $\left.\mathrm{MgSO}_{4}\right)$ on pine and found $\mathrm{H}_{2} \mathrm{SO}_{4}$ as the most effective catalyst in terms of ethanol yield. However, in terms of digestibility, $\mathrm{NaOH}$ was found to be effective when its concentration was increased by $2 \% . \mathrm{H}_{2} \mathrm{SO}_{4}$ has high reactivity therefore has proven to be a very strong catalyst but at the same time it is toxic, corrosive and is inhibitory in nature. The main drawback of this process is the high cost of the solvents, though this drawback can be minimized by recovering and recycling solvents through evaporation and condensation. Removal of solvents is very important because the solvent may cause negative effect on growth of microorganisms, enzymatic hydrolysis, and fermentation (Agbor et al. 2011). Also, organosolv is less preferred due to high risk involved in handling harsh organic solvents that are highly flammable. In absence of proper safety measures, it can cause severe damage leading to large fire explosions. The Battelle is a type of organosolv method that treats the biomass with mixture of phenol, $\mathrm{HCl}$, and water at temperature $100{ }^{\circ} \mathrm{C}$ and pressure $1 \mathrm{~atm}$ (Villaverde et al. 2010). Acid is responsible for the depolymerization of lignin as well as it hydrolyses the hemicellulose portion of the biomass. Lignin is dissolved in the phenol while the sugars (monosaccharides) are found in the aqueous phase upon cooling. Likewise formasolv is a type of organosolv involving formic acid, water, and $\mathrm{HCl}$. Lignin is soluble in formic acid and the pretreatment process can be carried out at low temperature and pressure (Zhao and Liu 2012). Unlike formasolv, ethanosolv (involving ethanol) is operated at high temperature and pressure and recovers value-added products namely cellulose, hemicellulose, and pure lignin. Further purification may be carried out through ionic liquids which are discussed later in this review (Prado et al. 2012). The less toxic nature of ethanol as compared to methanol and it being the final product makes it more popular as compared to other solvents (Kim et al. 2011a, b). However, presence of ethanol inhibits the performance of hydrolytic enzymes, therefore lower ethanol: water is used for hydrolysis of hemicellulose and enzymatic degradation of pretreated biomass (Huijgen et al. 2008). Also, nearly complete recovery of ethanol and water is a major advantage which reduces the operation cost (Koo et al. 2012; Alriols et al. 2010). Mesa et al. (2011) applied ethanosolv on sugarcane bagasse for production of reducing sugars. $29.1 \%$ reducing sugars were produced by $30 \%$ ethanol for $60 \mathrm{~min}$ at $195{ }^{\circ} \mathrm{C}$. Similarly, horticultural waste was pretreated by a modified method using ethanol under mild conditions for bioethanol production. Pretreatment resulted in hydrolysate containing $15.4 \%$ reducing sugar after $72 \mathrm{~h}$, which after fermentation produced $1.169 \%$ ethanol in $8 \mathrm{~h}$ using Saccharomyces cerevicae (Geng et al. 2012). Hideno et al. (2013) reported utilization of alcohol-based organosolv treatment in combination with ball milling for pretreatment of Japanese cypress (Chamaecyparis obtusa). They observed that combination of alcohol-based organosolv treatment in mild conditions and short time ball milling had a synergistic effect on the enzymatic digestibility. Ichwan and Son (2011) studied the effect of various solvents such as ethanol-water, ethylene glycol-water, and acetic acid-water mixture to extract cellulose from oil palm pulp. The yield of organosolv pulping with ethylene glycol-water, ethanol-water, and acetic acid-water mixture was 50.1, 48.1, and $41.7 \%$, respectively. Panagiotopoulos et al. (2012) treated poplar wood chips with steam followed by organosolv treatment for separating hemicellulose, lignin, and cellulose components. Lignin extraction was found to increase to $66 \%$, while $98 \%$ of the cellulose was recovered by two stage pretreatment process and $88 \%$ of cellulose was hydrolyzed to glucose after $72 \mathrm{~h}$.

\section{lonic liquids}

Ionic liquids have received great attention in last decade for the pretreatment of lignocellulosic biomass. Ionic liquids are comparatively a new class of solvents which are entirely made of ions (cations and anions), have low melting points $\left(<100{ }^{\circ} \mathrm{C}\right)$, negligible vapor pressure, high thermal stabilities, and high polarities (Zavrel et al. 2009; Behera et al. 2014). Imidazolium salts are the most commonly used ILs. ILs are assumed to compete with lignocellulosic components for hydrogen bonding there by disrupting its network (Moultrop et al. 2005). Table 2 lists various ionic liquids used for the treatment of a variety of biomasses.

According to Li et al. (2011), with suitable selection of anti-solvents up to $80 \%$ lignin and hemicellulose can be fractionated. Dadi et al. (2006) used 1-butyl-3-methylimidazolium chloride $(\mathrm{Bmim}-\mathrm{Cl})$ for pretreatment of Avicel-PH-101 reported 50- and 2-fold increase in enzymatic hydrolysis rate and yield, respectively, as compared to untreated Avicel. Liu and Chen (2006) used $\mathrm{Bmim}-\mathrm{Cl}$ for pretreating wheat straw and found significant improvement in enzymatic hydrolysis yield. They found that $\mathrm{Bmim}-\mathrm{Cl}$ modified structure of wheat 
Table 2 Different types of ionic liquids applied for the pretreatment of different biomass (Bajpai 2016)

\begin{tabular}{|c|c|c|}
\hline Biomass & Ionic liquid & Abbreviated symbol \\
\hline Poplar wood & 1-Ethyl-3-methylimidazolium diethyl phosphate-acetate & Emim-Ac \\
\hline Pine & 1-Allyl-3-methylimidazolium chloride & Amim-Cl \\
\hline Eucalyptus & Ethyl-3-methylimidazolium diethyl phosphate-acetate & Emim-Ac \\
\hline Spruce & 1-Allyl-3-methylimidazolium chloride & Amim-Cl \\
\hline Bagasse & Ethyl-3-methylimidazolium diethyl phosphate-acetate & Emim-Ac \\
\hline Switch grass & Ethyl-3-methylimidazolium diethyl phosphate-acetate & Emim-Ac \\
\hline Bamboo & 1-Ethyl-3-methylimidazolium diethyl phosphate-glycine & Emim-Gly \\
\hline \multirow[t]{2}{*}{ Wheat straw } & 1-Allyl-3-methylimidazolium chloride and chloride & Amim-Ac \\
\hline & 1-Butyl-3-methylimidazolium-acetate & Bmim-Ac \\
\hline Water hyacinth & 1-Butyl-3-methylimidazolium-acetate & Bmim-Ac \\
\hline \multirow[t]{2}{*}{ Rice husk } & 1-Butyl-3-methylimidazolium-chloride & Bmim-Cl \\
\hline & 1-Ethyl-3-methylimidazolium diethyl phosphate-acetate & Emim-Ac \\
\hline Rice straw & Cholinium amino acids & Ch-Aa \\
\hline Kenaf powder & Cholinium acetate & Ch-Ac \\
\hline
\end{tabular}

straw by reducing the polymerization and crystallinity and solubilizing cellulose and hemicellulose. Sugarcane bagasse pretreated with 3-N-methylmorpholine-N-oxide (NMMO) showed twofold increase in enzymatic hydrolysis yield as compared to untreated bagasse (Kuo and Lee 2009). Ionic liquids has been able to effectively pretreat lignocellulosic biomass, however, there are certain challenges that need to be addressed such as high cost of ILs, difficulty in recycling and reuse, inhibitor generation etc.

\section{Deep eutectic solvents}

These are relatively a new class of solvents having many characteristics similar to ionic liquids. A deep eutectic solvent (DES) is a fluid generally composed of two or three cheap and safe components that are capable of selfassociation, often through hydrogen bond interactions, to form a eutectic mixture with a melting point lower than that of each individual component (Zhang et al. 2012a, b). These DES were able to solve some of the key concerns associated with ILs. Deep eutectic solvents can be described by the general formula

$$
\mathrm{Cat}^{+} \mathrm{X}^{-} \mathrm{zY}
$$

where $\mathrm{Cat}^{+}$is in principle any ammonium, phosphonium, or sulfonium cation, and $\mathrm{X}$ is a Lewis base, generally a halide anion. The complex anionic species are formed between $\mathrm{X}^{-}$and either a Lewis or Brønsted acid $\mathrm{Y}$ ( $z$ refers to the number of $\mathrm{Y}$ molecules that interact with the anion) (Smith et al. 2014). Most of the DESs have used choline chloride $(\mathrm{ChCl})$ as hydrogen bond acceptor. $\mathrm{ChCl}$ is low-cost, biodegradable, and non-toxic ammonium salt which can be extracted from biomass. $\mathrm{ChCl}$ is able to synthesize DESs with hydrogen donors such as urea, carboxylic acids, and polyols. Although DESs are similar to ILs in terms of physical behavior and physical properties, DESs cannot be considered as ionic liquids due to the fact that DESs are not entirely composed of ionic species and can be obtained from non-ionic species (Zhang et al. 2012a, b).

\section{Natural deep eutectic solvents}

In the recent past, a large number of natural products have been brought into the range of ILs and DES. These products include choline, urea, sugars, amino acids, and several other organic acids (Dai et al. 2013). Such solvents obtained from natural sources are termed as Natural Deep Eutectic Solvents (NADES). Unlike ILs, NADES are cost effective, easier to synthesize, non-toxic, biocompatible, and highly biodegradable. Moreover, many studies recovered and reused these novel solvents with high efficiency. NADES are prepared by the complex formation between a hydrogen acceptor and a hydrogen bond donor. The decrease in melting point of the prepared solvent mixtures is due to the charge delocalization of the raw individual components. Foreseeing the potentiality of NADES in diverse applications, these solvents are regarded as the solvents for the twenty first century (Paiva et al. 2014). Moreover, recent research on lignocellulosic feedstock pretreatment with NADES reagents showed high specificity towards lignin solubilisation and extraction of high purity lignin from agricultural residue such as rice straw (Kumar et al. 2016). Despite having a lot of potential for the extraction of natural products, the high viscosity of NADES is an obvious disadvantage. Dai et al. (2015) studied the dilution effect on the physicochemical properties of NADES. FT-IR and ${ }^{1} \mathrm{H}$ NMR 
studies showed intense $\mathrm{H}$-bonds between the two components of NADES system. However, the dilution with water weakened the interactions. At around 50\% (v/v) dilution with water, the intense hydrogen interactions disappeared completely. The viscosity of NADES reduced to the order of water and conductivity increased up to 100 times for some NADES reagents. Along with pretreatment, NADES can prove to be a game changer concept in pharma, food processing, and enzyme industries.

\section{Physico-chemical pretreatment Steam explosion}

Steam pretreatment is one of the most commonly used physicochemical methods for pretreatment of lignocellulosic biomass. Earlier, this method was known as steam explosion because of the belief that an explosive action on the biomass was required to prepare them for hydrolysis (Agbor et al. 2011). Due to the changes that occur during this process, this method is also called 'auto hydrolysis.' Steam pretreatment is typically a combination of mechanical forces (pressure drop) and chemical effects (autohydrolysis of acetyl groups of hemicellulose). In this process, biomass is subjected to high pressure (0.7-4.8 MPa) saturated steam at elevated temperatures (between 160 and $260{ }^{\circ} \mathrm{C}$ ) for few seconds to minutes which causes hydrolysis and release of hemicellulose. The steam enters the biomass expanding the walls of fibers leading to partial hydrolysis and increasing the accessibility of enzymes for cellulose. After this the pressure is reduced to atmospheric condition (Rabemanolontsoa and Saka 2016). During this pretreatment, the hydrolysis of hemicellulose into glucose and xylose monomers is carried out by the acetic acid produced from the acetyl groups of hemicellulose; hence this process is also termed as autohydrolysis (Mosier et al. 2005). The factors that affect steam pretreatment are temperature, residence time, biomass size, and moisture content (Rabemanolontsoa and Saka 2016). Wright (1988) found low temperature and longer residence time $\left(190{ }^{\circ} \mathrm{C}\right.$ for $\left.10 \mathrm{~min}\right)$ better as compared to high temperature and lower residence time $\left(270{ }^{\circ} \mathrm{C}\right.$ for $\left.1 \mathrm{~min}\right)$ due to less fermentation inhibitory product formation in the earlier process. Several biomasses have shown positive effects on pretreatment with steam such as poplar wood (Populus tremuloides) (Grous et al. 1986), pine chips, French maritime pine (Pinus pinaster), rice straw, bagasse, olive stones, giant miscanthus (Miscanthus giganteus), and spent Shiitake mushroom media (Jacquet et al. 2012). The efficiency of steam pretreatment can be effectively enhanced in the presence of catalysts such as $\mathrm{H}_{2} \mathrm{SO}_{4}, \mathrm{CO}_{2}$ or $\mathrm{SO}_{2}$. Out of these catalysts, acid catalyst has been found to most successful in terms of hemicellulose sugar recovery, decreased production of inhibitory compounds and improved enzymatic hydrolysis. Steam pretreatment is found to be effective for the pretreatment of hardwoods and agricultural residues, though acid catalyst is added in case of soft woods for effective pretreatment. Limited use of chemicals, low energy requirement, no recycling cost and environment friendly are some of the advantages of steam pretreatment method. On the other hand, the possibility of formation of fermentation inhibitors at high temperature, incomplete digestion of lignin-carbohydrate matrix and the need to wash the hydrolysate which decreases the sugar yield by $20 \%$ are few disadvantages associated with steam pretreatment (Agbor et al. 2011).

\section{Liquid hot water}

This method, also called as hot compressed water is similar to steam pretreatment method but as the name suggests, it uses water at high temperature $\left(170-230{ }^{\circ} \mathrm{C}\right)$ and pressure (up to $5 \mathrm{MPa}$ ) instead of steam. This leads to hydrolysis of hemicellulose and removes lignin making cellulose more accessible. This also avoids the formation of fermentation inhibitors at high temperatures (Yang and Wyman 2004). Different researchers have described liquid hot water (LHW) with different terms such as solvolysis, hydrothermolysis, aqueous fractionation and aquasolv (Agbor et al. 2011). LHW can be performed in three different ways based on the direction of flow of water and biomass into reactor. (1) Co-current pretreatment, in which both the slurry of biomass and the water is heated to the required temperature and held at the pretreatment conditions for controlled residence time before being cooled. (2) Counter current pretreatment, in which the hot water is pumped against the biomass in controlled conditions. (3) Flow through pretreatment where the biomass acts like a stationary bed and hot water flows through the biomass and the hydrolyzed fractions are carried out of the reactor. Abdullah and coworkers (2014) conducted studies on LHW to investigate the hydrolysis performance. The optimization could not be carried out at same severity due to the difference in rate of hydrolysis of cellulose and hemicellulose. Therefore, a two-step hot compressed water treatment was proposed. First stage is carried out at low severity for hydrolyzing the hemicellulose while second stage is carried out at high severity for depolymerization of cellulose and increase sugar yield. Ogura et al. (2013) and Phaiboonsilpa (2010) applied two-step hydrolysis (I step: $230{ }^{\circ} \mathrm{C}-10 \mathrm{MPa}-15 \mathrm{~min}$; II step: $275^{\circ} \mathrm{C}-10 \mathrm{MPa}-15 \mathrm{~min}$ ) to Japanese beech, Japanese cedar, Nipa frond and rice straw and found to solubilize $92.2,82.3,92.4$, and $97.9 \%$ of the starting biomass, respectively. This has proved that LHW is capable of acting on a large variety of biomass including softwoods (Rabemanolontsoa and Saka 2016). Low-temperature requirement, minimum formation of inhibitory compounds and 
low cost of the solvent are some of the advantages associated with LHW. However, it requires large amount of energy in downstream processing due to large amount of water involved (Agbor et al. 2011).

\section{Wet oxidation}

Wet oxidation is one of the simple methods of lignocellulosic pretreatment where the air/oxygen along with water or hydrogen peroxide is treated with the biomass at high temperatures (above $120{ }^{\circ} \mathrm{C}$ for $30 \mathrm{~min}$ ) (Varga et al. 2003). Earlier this method as also used for waste water treatment and soil remediation (Chaturvedi and Verma 2013). This method is most suitable for lignin enriched biomass residues. The efficiency of wet oxidation is dependent on three factors: oxygen pressure, temperature, and reaction time. In this process, when the temperature is raised above $170{ }^{\circ} \mathrm{C}$, water behaves like an acid and catalyzes hydrolytic reactions. The hemicelluloses are broken down into smaller pentose monomers and the lignin undergoes oxidation, while the cellulose is least affected by wet oxidation pretreatment. Besides these, reports on addition of chemical agents like sodium carbonate and alkaline peroxide in wet oxidation reduced the reaction temperature, improved hemicellulose degradation and decreased the formation of inhibitory components such as furfurals and furfuraldehydes (Banerjee et al. 2011). This pretreatment method is unlikely to reach industrial scale of biomass pretreatment because of the high cost of the hydrogen peroxide and the combustible nature of the pure oxygen (Bajpai 2016). Szijártó et al. (2009) applied wet oxidation for the pretreatment of common reed (Phragmites australis). The treatment resulted in three fold increase in digestibility of reed cellulose by cellulase as compared to control. $51.7 \%$ of hemicellulose and $58.3 \%$ of lignin was solubilised and $82.4 \%$ of cellulose got converted into cellulose on enzymatic hydrolysis of the pretreated fibers. The pretreated fibers produced $0.87 \%$ ethanol when underwent simultaneous saccharification and fermentation. Banerjee et al. (2009) optimized the wet oxidation conditions for rice husk for the production of ethanol. The optimized conditions of $0.5 \mathrm{MPa}$ pressure, $185^{\circ} \mathrm{C}$ temperature for $15 \mathrm{~min}$ yielded $67 \%$ of cellulose, removed $89 \%$ lignin, and solubilised $70 \%$ hemicellulose. Reducing sugar yields up to $70 \%$ have been obtained by utilizing this pretreatment process. Alkaline Peroxide-Assisted Wet Air Oxidation (APAWAO) treatment on rice husk resulted in solubilization of 67 and 88 $w t \%$ of hemicellulose and lignin, respectively. The glucose amount increased 13-fold as compared from untreated rice husk (Banerjee et al. 2011). This pretreatment method is unlikely to reach industrial scale of biomass pretreatment because of the high cost of the hydrogen peroxide and the combustible nature of the pure oxygen (Bajpai 2016).

\section{SPORL treatment}

Sulfite pretreatment to overcome recalcitrance of lignocellulose (SPORL) is a popular and efficient pretreatment method for lignocellulosic biomass (Xu et al. 2016). It is carried out in a combination of two steps: First, the biomass is treated with calcium or magnesium sulfite to remove hemicellulose and lignin fractions. In the second step, the size of the pretreated biomass is reduced significantly using mechanical disk miller. Zhu et al. (2009) studied the effect of SPORL pretreatment on spruce chips using $8-10 \%$ bisulfite and $1.8-3.7 \%$ sulfuric acid at $180{ }^{\circ} \mathrm{C}$ for $30 \mathrm{~min}$. After $48 \mathrm{~h}$ of hydrolysis with $14.6 \mathrm{FPU}$ cellulase $+22.5 \mathrm{CBU} \beta$-glucosidase per gram of substrate, more than $90 \%$ substrate was converted to cellulose. Also, only $0.5 \%$ hydroxymethyl furfural (HMF) and $0.1 \%$ furfural (fermentation inhibitors), respectively, were formed as compared to 5\% HMF and 2.5\% furfural formation during the acid catalyzed steam pretreatment of spruce. The amount of HMF and furfural was also reported to decrease with increasing bisulfite. The possible reason is that at same acid charge, higher amount of bisulfite leads to higher $\mathrm{pH}$ which reduces the decomposition of sugars to HMF and furfural.

SPORL pretreatment on switchgrass was carried out by Zhang et al. (2013) with temperature ranging between 163 and $197{ }^{\circ} \mathrm{C}$ for a period ranging from 3-37 min with sulfuric acid dosage $(0.8-4.2 \%)$ and sodium sulfite dosage $(0.6-7.4 \%)$. The results found improved digestibility of switchgrass by removing hemicellulose, dissolving lignin partially and decreasing hydrophobicity of lignin by sulfonation. SPORL pretreated switchgrass was hydrolysed by $83 \%$ in $48 \mathrm{~h}$ with 15 FPU cellulase and $30 \mathrm{CBU}$ $\beta$-glucosidase/g cellulose. SPORL pretreatment method when compared with dilute acid and alkali pretreatments, was found to give the highest substrate yield of $77.2 \%$ as compared to 68.1 and $66.6 \%$ by dilute acid and alkali pretreatment, respectively. Sodium sulfide and sodium sulfite along with sodium hydroxide were applied for pretreatment of corncob, bagasse, water hyacinth and rice husk. Pretreatment under optimized conditions yielded 97\% lignin and 93\% hemicellulose from water hyacinth and rice husk, and 75\% lignin and 90\% hemicellulose were removed from bagasse and rice husk (Idrees et al. 2013).

SPORL pretreatment has been popular in the recent times because of its versatility, efficiency, and simplicity. It reduces the energy consumption to $1 / 10$ required for the reduction of size of biomass. It has very high conversion rate of cellulose to glucose and maximizes 
hemicellulose and lignin removal and recovery. It has the capacity to process a variety of biomass and has excellent scalability for commercial production by retrofitting into existing mills for production of biofuels. However, certain issues such as sugar degradation, requirement of large volumes of water for post-pretreatment washing and high cost of recovering pretreatment chemicals need to be addressed for making SPORL a cost effective pretreatment technology (Bajpai 2016).

\section{Ammonia-based pretreatment}

Methods that use liquid ammonia for the pretreatment of lignocellulosic biomass are Ammonia fiber explosion (AFEX), Ammonia recycle percolation (ARP) and soaking aqueous ammonia (SAA). AFEX is conducted at ambient temperature while ARP is conducted at high temperatures (Agbor et al. 2011) SAA is a form of AFEX which treats biomass through aqueous ammonia in a batch reactor at $30-60{ }^{\circ} \mathrm{C}$ which decreases the liquid through-put during process of pretreatment (Kim and Lee 2005a). In AFEX, lignocellulosic biomass is heated with liquid ammonia (in 1:1 ratio) in a closed vessel at temperature $60-90{ }^{\circ} \mathrm{C}$ and pressure above $3 \mathrm{MPa}$ for 30-60 min. After holding the desired temperature in vessel for $5 \mathrm{~min}$, valve is opened which explosively releases the pressure leading to evaporation of ammonia and drop in temperature of the system (Alizadeh et al. 2005). It is similar to steam explosion but ammonia is used instead of water (Rabemanolontsoa and Saka 2016). Lignocellulosic biomass when treated with ammonia at high pressure and given temperature causes swelling and phase change in cellulose crystallinity of biomass leading to increase in the reactivity of leftover carbohydrates after pretreatment. The lignin structure gets modified which increases the water holding capacity and digestibility. Unlike other pretreatment methods, AFEX treatment does not produce inhibitors, which is highly desirable for downstream processing. Besides, the overall cost of the pretreatment process is significantly low due to the absence of additional steps like water washing, detoxification, recovery, and reuse of large quantities of water. More than $90 \%$ of celluloses and hemicelluloses could be converted to fermentable sugars if pretreated with AFEX under optimized conditions of ammonia loading, temperature, pressure, moisture content and pretreatment time (Uppugundla et al. 2014). Moreover, the ammonia could be recovered and recycled to decrease the overall cost of the pretreatment process.

Another process that utilizes ammonia is ammonia recycle percolation (ARP). In this process, aqueous ammonia (5-15 wt\%) is passed through a reactor containing biomass. The temperature range is between 140 and $210{ }^{\circ} \mathrm{C}$ with a reaction time of $90 \mathrm{~min}$ and percolation rate is $5 \mathrm{~mL} / \mathrm{min}$ after which the ammonia is recycled (Sun and Cheng 2002; Kim et al. 2008). ARP is capable of solubilizing hemicellulose but cellulose remains unaffected (Alvira et al. 2010). The disadvantage with ARP is high requirement of energy to maintain process temperature. Both AFEX and ARP have been found to effective for herbaceous plants, agricultural residues and MSW. ARP pretreatment is found effective for hardwoods also (Kim and Lee 2005b). Another technology soaking aqueous ammonia (SAA) requires less energy as it is performed at low temperature $\left(30-75^{\circ} \mathrm{C}\right)$.

\section{$\mathrm{CO}_{2}$ explosion}

This process carries out the pretreatment of biomass through supercritical $\mathrm{CO}_{2}$ which means the gas behaves like a solvent. The supercritical $\mathrm{CO}_{2}$ is passed through a high pressure vessel containing the biomass (Kim and Hong 2001). The vessel is heated to the required temperature and kept for several minutes at high temperatures (Hendricks and Zeeman 2009). $\mathrm{CO}_{2}$ enters the biomass at high pressure and forms carbonic acid which hydrolyses the hemicellulose. The pressurized gas when released disrupts the biomass structure which increases the accessible surface area (Zheng et al. 1995). This pretreatment method is not suitable for biomass having no moisture content. Higher the moisture content in the biomass, higher the hydrolytic yield (Kim and Hong 2001). Low cost of carbon dioxide, low temperature requirement, high solid capacity, and no toxin formation makes it an attractive process. However, high cost of reactor which can tolerate high pressure conditions is a big obstacle in its application on large scale (Agbor et al. 2011).

\section{Oxidative pretreatment}

It involves treatment of lignocellulosic biomass by oxidizing agents such as hydrogen peroxide, ozone, oxygen or air (Nakamura et al. 2004). A number of chemical reactions such as electrophilic substitution, side chain displacements, and oxidative cleavage of aromatic ring ether linkages may take place during oxidative pretreatment. This process causes delignification by converting lignin to acids, which may act as inhibitors. Therefore, these acids need to be removed (Alvira et al. 2010). A major drawback of oxidative pretreatment is that it damages a significant amount of hemicellulose making it unavailable for fermentation (Lucas et al. 2012). The most commonly employed oxidizing agent is hydrogen peroxide. It has been found that hydrolysis of hydrogen peroxide leads to formation of hydroxyl radicals which are responsible for degradation of lignin and production of low molecular weight products. Removal of lignin from lignocellulose exposes cellulose and hemicellulose leading to increased enzymatic hydrolysis (Hammel et al. 2002). The following 
enzymatic hydrolysis yield could reach up to $95 \%$. Yu et al. (2009) combined oxidative pretreatment followed by biological treatment with Pleurotus ostreatus. At optimum conditions of hydrogen peroxide pretreatment i.e., $2 \% \mathrm{H}_{2} \mathrm{O}_{2}$ for $48 \mathrm{~h}$ followed by biological pretreatment for 18 days yielded $39.8 \%$ total sugar and $49.6 \%$ glucose. This was about 5.8 and 6.5 times more as compared to fungal pretreatment alone for 18 days. Saha and Cotta (2007) has reported that peroxide pretreatment under alkaline conditions (addition of $\mathrm{NaOH}$ ) increased the production of reducing sugars with more than $96 \%$ cellulosic conversion as compared to absence of alkali. Cao et al. (2012) performed pretreatment of sweet sorghum bagasse through different pretreatment processes and found the highest yield with dilute $\mathrm{NaOH}$ followed by $\mathrm{H}_{2} \mathrm{O}_{2}$ pretreatment. The highest cellulose hydrolysis yield was $74.3 \%$, total sugar yield was $90.9 \%$ and ethanol concentration was $0.61 \%$ which was $5.9,9.5$, and 19.1 times higher as compared to control.

\section{Biological pretreatment}

In comparison to conventional chemical and physical pretreatment methods, biological pretreatment is considered as an efficient, environmentally safe and low-energy process. Nature has abundant cellulolytic and hemicellulolytic microbes which can be specifically targeted for effective biomass pretreatment (Vats et al. 2013). Biological pretreatments are carried out by microorganisms such as brown, white, and soft-rot fungi which mainly degrade lignin and hemicellulose and little amount of cellulose (Sánchez 2009). Degradation of lignin by whiterot fungi occurs due to the presence of peroxidases and laccases (lignin degrading enzymes) (Kumar et al. 2009). The white-rot fungi species commonly employed for pretreatment are Phanerochaete chrysosporium, Ceriporia lacerata, Cyathus stercolerus, Ceriporiopsis subvermispora, Pycnoporus cinnarbarinus and Pleurotus ostreaus. Besides these other basidiomycetes species were also studied for breakdown of several lignocellulosic feedstocks. Among these Bjerkandera adusta, Fomes fomentarius, Ganoderma resinaceum, Irpex lacteus, Phanerochaete chrysosporium, Trametes versicolor, and Lepista nuda are well studied. These species have been reported to show high delignification efficiency (Kumar et al. 2009; Shi et al. 2008). Table 3 summarizes different microorganisms involved in pretreatment strategies and their effects on various biomasses. Pretreatment of wheat straw by fungi (fungal isolate RCK-1) for 10 days resulted in increase of fermentable sugars and decrease in fermentation inhibitors. Although the biological pretreatment is highly intriguing, the rate of hydrolysis of lignocellulosic fractions is too slow which severely hampers to be foreseen as a potential pretreatment method at an industrial scale (Sun and Cheng 2002). In order to make biological pretreatment at par with other pretreatment methods, more basidiomycetes fungi should be tested for its ability to delignify the biomass effectively at a faster rate.

\section{Combined biological pretreatment}

Studies have found that a combination of another pretreatment process with biological pretreatment process is more effective as compared to a single pretreatment process. Wang et al. (2012) combined biological pretreatment with liquid hot water pretreatment method for better enzymatic saccharification of Populus tormentosa. This combination reported highest hemicellulose removal (92.33\%) resulting in 2.66-fold increase in glucose yield as compared to pretreatment carried out with liquid hot water alone. Yu et al. (2009) studied the novel combination of either physical or chemical pretreatment with biological pretreatment on rice husk. Physical pretreatment was carried out using ultrasound while chemical pretreatment was carried out using $\mathrm{H}_{2} \mathrm{O}_{2}$. Biological pretreatment was carried out using $P$. ostreatus. The combined pretreatment of rice husk carried out using $2 \% \mathrm{H}_{2} \mathrm{O}_{2}$ for $48 \mathrm{~h}$ along with $P$. ostreatus was found more effective as compared to single step pretreatment using $P$. ostreatus for 60 days. Lignin removal was also found significantly higher as compared to one step treatment. Balan et al. (2008) studied and found that pretreatment of rice husk with $P$. ostreatus followed by AFEX pretreatment produced high glucan and xylan conversion as compared to a single pretreatment with AFEX. The combination of mild acid pretreatment $\left(0.25 \% \mathrm{H}_{2} \mathrm{SO}_{4}\right)$ and biological pretreatment using Echinodontium.taxodii on water hyacinth was found more effective than one step pretreatment. The reducing sugars yield doubled as compared to single step acid pretreatment method (Ma et al. 2010). Sawada et al. (1995) combined steam explosion and pretreatment by $P$. chrysosporium for the enzymatic saccharification of plant wood. The saccharification of wood increased when treated with $P$. chrysosporium prior to steam explosion. Maximum production of reducing sugar was observed when wood was treated with $P$. chrysosporium for 28 days followed by steam explosion at $215{ }^{\circ} \mathrm{C}$ for 60-65 min.

\section{Applications of biomass pretreatment}

Biomass pretreatment results in production of several value-added products. Although, here we have described in brief but this topic is beyond the scope of this review and readers are suggested to refer recent review on various products obtained from pretreated lignocellulosic biomass (Putro et al. 2016). Several valuable products can be obtained through lignocellulosic biomass. Among 
Table 3 Different biological pretreatment strategies involved for pretreatment of lignocellulosic biomass and its advantages (adapted from Sindhu et al. 2016)

\begin{tabular}{|c|c|c|c|}
\hline Microorganism & Biomass & Major effects & References \\
\hline Punctualaria sp. TUFC 20056 & Bamboo culms & $50 \%$ lignin removal & Suhara et al. (2012) \\
\hline Irpex lacteus & Corn stalks & $82 \%$ of hydrolysis yield & Du et al. (2011) \\
\hline Fungal consortium & Straw & 20-fold increase in hydrolysis & Taha et al. (2015) \\
\hline P.ostreatus/P.pulmonarius & Eucalyptus grandis saw dust & 20-fold increase in hydrolysis & Castoldi et al. (2014) \\
\hline P.chrysosporium & Rice husk & - & Potumarthi et al. (2013) \\
\hline Fungal consortium & Corn stover & 43.8\% lignin removal/sevenfold increase in hydrolysis & Song et al. (2013) \\
\hline Ceriporiopsis subvermispora & Wheat straw & Minimal cellulose loss & Cianchetta et al. (2014) \\
\hline Ceriporiopsis subvermispora & Corn stover & 2- to 3-fold increase in reducing sugar yield & Wan and Li (2011) \\
\hline Fungal consortium & Plant biomass & Complete elimination of use of hazardous chemicals & Dhiman et al. (2015) \\
\hline
\end{tabular}

which biofuel and chemicals are well known and widely studied.

\section{Biofuels}

Several biofuels are obtained through lignocellulosic biomass such as bio-oil, bioethanol, biohydrogen, biogas, syngas etc. Bio-oil is produced through pyrolysis along with biochar, tar and gases. Bio-oil is produced by fast depolymerisation of lignocellulose components viz. hydroxyaldehydes, sugars, hydroxyketones, carboxylic acids, and phenols. Bioethanol can be produced through 5 different methods: separate hydrolysis and fermentation (SHF), simultaneous saccharification and fermentation (SSF), simultaneous and saccharification co-fermentation (SSCF), consolidated bioprocessing (CBP), and integrated bioprocessing (IBP) (Sarkar et al. 2012; Jagmann and Philipp 2014). SSF is the most promising among these processes because of its low-cost and high product yield. IBP is another promising process which involves treatment with microorganisms at every step in a single step. However, there is no reported work on pretreatment through IBP (Chandel et al. 2015). Biohydrogen can be produced from lignocellulosic biomass through thermochemical (gasification and pyrolysis) or biological routes (Ni et al. 2006). Through pyrolysis, hydrogen can be produced through fast or flash pyrolysis (Putro et al. 2016). Hydrogen can produced through gasification by partial oxidation and steam reformation followed by waster-gas shift reaction. Two processes to produce biohydrogen through biological route are: photo fermentation which is light dependant and dark fermentation which is light independent (Sivagurunathan et al. 2016). Although biogas and syngas have similar composition $\left(\mathrm{CO}_{2}, \mathrm{CH}_{4}\right.$, $\mathrm{H}_{2}$, and $\mathrm{N}_{2}$ ), they are produced through two different processes. Biogas is produced through anaerobic digestion which comprises of four steps: hydrolysis, acidogenesis, acetogenesis, and methanogenesis (Taherzadeh and Karimi 2008) while syngas is produced by gasification carried out at lower temperature due to high reactivity of biomass. Biomass gasification has three types of processes namely: (1) pyrolysis which involves anaerobic decomposition of biomass at high temperature, (2) partial oxidation which requires less amount of oxygen as compared to oxidation, and (3) steam gasification which involves the reaction of water with biomass.

\section{Bioproducts}

The chemicals from lignocellulosic biomass can be derived either through carbohydrate source or through lignin. (1) The simplest chemical derived from carbohydrate is furfural and 5-hydroxymethylfurfural (HMF), produced through acid catalyzed dehydration of $\mathrm{C}_{5}$ and $\mathrm{C}_{6}$ sugars (Delidovich et al. 2016). Sugar alcohols such as sorbitol and xylitol are obtained by the hydrogenation of hexose and pentose (Romero et al. 2016). Also, glycerol, widely used for making bio-solvents, polymers, surfactants etc. can be produced by hydrogenolysis of sorbitol and xylitol (Choi et al. 2015). Also lactic acid and succinic acid can be obtained by the biological conversion caused by bacteria and mold. (2) Lignin has been used to generate heat in the earlier days. In the recent times lignin has been a rich source of valuable products like phenolic compounds. The basic principle behind the conversion of lignin to phenolic compounds is depolymerization. Different ways to convert lignin to phenolics compounds are liquefaction (Kang et al. 2013), oxidation (Ma et al. 2015), solvolysis (Kleinert and Barth 2008), hydrocracking (Yoshikawa et al. 2013) and hydrolysis (Roberts et al. 2011). Lignocellulose biomass has also been used for development of advanced technology products for energy storage, transportation, medical applications, biosensing, environmental remediation etc. (Wang et al. 2013; Brinchi et al. 2013; Yang et al. 2013). 


\section{Conclusion}

The presence of lignin in the biomass inhibits the hydrolysis of cellulose and hemicellulose. Therefore, extensive research has been carried out for developing various pretreatment techniques for delignification of biomass. However, critical analysis of pretreatment methods bring us to a conclusion that pretreatment method is a 'tailor-made' process for every individual biomass which should be meticulously selected and planned based on the characteristic properties of biomass. Also, it can be concluded that till date a single pretreatment method has not been established which can carry out complete delignification of biomass in an economic and environment friendly manner. Though, combined pretreatment methods have been successful to an extent, still a lot of research needs to be done in developing combined pretreatment methods to their full potential. This critical review comprising of physical, chemical, physicochemical and biological pretreatment processes along with their advantages and disadvantages will help the researcher in planning, selection, and development of pretreatment process for various lignocellulosic biomass.

\section{Authors' contributions}

AKK and SS designed and wrote the review. Both authors read and approved the final manuscript.

\section{Acknowledgements}

The authors are thankful to the Director, Sardar Patel Renewable Energy

Research Institute, Gujarat, India, for support of this research.

\section{Competing interests}

The authors declare that they have no competing interests.

\section{Availability of data and material}

All the authors have agreed to provide the data and material for open access.

\section{Consent for publication}

All the authors have approved the consent for publishing the manuscript.

\section{Ethics approval and consent to participate}

All the authors have read and agreed the ethics for publishing the manuscript.

\section{Funding}

The research work is financially supported by Indian Council of Agricultural Research (ICAR), under All India Co-ordinated Research Project (AICRP) -EAAI program, Govt. of India with Grant Number WN/RES/DRETLBT/2014/3, Department of Biotechnology with Grant Number BT/PR12368/ $\mathrm{PDB} / 26 / 431 / 2014$.

Received: 18 October 2016 Accepted: 10 January 2017 Published online: 18 January 2017

\section{References}

Abdullah R, Ueda K, Saka S (2014) Hydrothermal decomposition of various crystalline celluloses as treated by semi-flow hot-compressed water. J Wood Sci 60:278-286

Agbor VB, Cicek N, Sparling R, Berlin A, Levin DB (2011) Biomass pretreatment: fundamentals toward application. Biotechnol Adv 29:675-685
Aimin T, Hongwei Z, Gang C, Guohui X, Wenzhi L (2005) Influence of ultrasound treatment on accessibility and regioselective oxidation reactivity of cellulose. Ultrason Sonochem 12:467-472

Alizadeh H, Teymouri F, Gilbert TI, Dale BE (2005) Pretreatment of switchgrass by ammonia fibre explosion (AFEX). Appl Biochem Biotechnol 121:1133-1141

Alriols MG, Garcia A, Llano Ponte R, Labidi J (2010) Combined organosolv and ultrafiltration lignocellulosic biorefinery process. Chem Eng J 157:113-120

Alriols MG, Tejado A, Blanco M, Mondragon I, Labidi J (2009) Agricultural palm oil tree residues as raw material for cellulose, lignin and hemicelluloses production by ethylene glycol pulping process. Chem Eng J 148:106-114

Alvira P, Tomas-Pejo E, Ballesteros M, Negro MJ (2010) Pretreatment technologies for an efficient bioethanol production process based on enzymatic hydrolysis: a review. Biores Technol 10:4851-4861

Bajpai P (2016) In Pretreatment of lignocellulosic biomass for biofuel production. Springer Briefs in Molecular Science, pp 17-70

Balan V, Souca LDC, Chundawat SPS, Vismeh R, Jones AD, Dale BEJ (2008) Mushroom-spent straw: a potential substrate for an ethanol based biorefinery. Ind Microbiol Biotechnol 35:293-301

Banerjee S, Sen R, Mudliar S, Pandey RA, Chakrabarti T, Satpute D (2011) Alkaline peroxide assisted wet air oxidation pretreatment approach to enhance enzymatic convertibility of rice husk. Biotechnol Prog 27:691-697

Banerjee S, Sen R, Pandey RA, Chakrabarti T, Satpute D, Giri BS, Mudliar S (2009) Evaluation of wet air oxidation as a pretreatment strategy for bioethanol production from rice husk and process optimization. Biomass Bioenerg 33:1680-1686

Behera S, Arora R, Nandhagopal N, Kumar S (2014) Importance of chemical pretreatment for bioconversion of lignocellulosic biomass. Renew Sustain Energy Rev 36:91-106

Ben GD, Miron J (1981) The effect of combined chemical and enzyme treatment on the saccharification and in vitro digestion rate of wheat straw. Biotechnol Bioeng 23:823-831

Boonmanumsin P, Treeboobpha S, Jeamjumnunja K, Luengnaremitchai A, Chaisuwan T, Wongkasemjit S (2012) Release of monomeric sugars from Miscanthus sinensis by microwave assisted ammonia and phosphoric acid treatments. Bioresour Technol 103:425-431

Brinchi L, Contana F, Fortunati E, Kenny JM (2013) Production of nanocrystalline cellulose from lignocellulosic biomass: technology and applications. Carbohydr Polym 94:154-169

Brodeur G, Yau E, Badal K, Collier J, Ramachandran KB, Ramakrishnan S (2011) Chemical and physicochemical pretreatment of lignocellulosic biomass: A review. Enzyme Res 2011:787532. doi:10.4061/2011/787532

Bussemaker MJ, Zhang D (2013) Effect of ultrasound on lignocellulosic biomass as a pretreatment for biorefinery and biofuel applications. Ind Eng Chem Res 52:3563-3580

Cao W, Sun C, Liu R, Yin R, Wu X (2012) Comparison of the effects of five pretreatment methods on enhancing the enzymatic digestibility and ethanol production from sweet sorghum bagasse. Bioresour Technol 111:215-221

Castoldi R, Bracht A, de Morais GR, Baesso ML, Correa RCG, Peralta RA, Moreira RFPM, Polizeli MT, de Souz CGM, Peralta RM (2014) Biological pretreatment of Eucalyptus grandis sawdust with white-rot fungi: study of degradation patterns and saccharification kinetics. Chem Eng J 258:240-246

Chandel AK, Goncalves BC, Strap JL, de Silva SS (2015) Biodelignification of lignocellulose substrates: an intrinsic and sustainable pretreatment strategy for clean energy production. Crit Rev Biotechn 35:281-293

Chang VS, Burr B, Holtzapple MT (1997) Lime pretreatment of switchgrass. Appl Biochem Biotechnol 63-65:3-19

Chaturvedi V, Verma P (2013) An overview of key pretreatment processes employed for bioconversion of lignocellulosic biomass into biofuels and value added products. 3. Biotech 3:415-431

Chen W, Yu H, Liu Y, Chen P, Zhang M, Hai Y (2011a) Individualization of cellulose nanofibers from wood using high-intensity ultrasonication combined with chemical pretreatments. Carbohy Polym 83:1804-1811

Chen WH, Tu YJ, Sheen HK (2011 b) Disruption of sugarcane bagasse lignocellulosic structure by means of dilute sulfuric acid pretreatment with microwave-assisted heating. Appl Energy 88:2726-2734 
Cheng YS, Zheng Y, Yu CW, Dooley TM, Jenkins BM, Gheynst JSV (2010) Evaluation of high solids alkaline pretreatment of rice straw. Appl Biochem Biotech 162:1768-1784

Choi S, Song CW, Shin JH, Lee SY (2015) Biorefineries for the production of top building block chemicals and their derivatives. Metab Eng 28:223-239

Cianchetta S, Maggio BD, Burzi PL, Galletti S (2014) Evaluation of selected white-rot fungal isolates for improving the sugar yield from wheat straw. Appl Biochem Biotechnol 173:609-623

Dadi AP, Varanasi S, Schall CA (2006) Enhancement of cellulose saccharification kinetics using an ionic liquid pretreatment step. Biotechnol Bioeng 95:904-910

Dai Y, van Spronsen J, Witkamp G-J, Verpoorte R, Choi YH (2013) Natural deep eutectic solvents as new potential media for green technology. Anal Chim Acta 766:61-68

Dai Y, Witkamp GJ, Verpoorte R, Choi YH (2015) Tailoring properties of natural deep eutectic solvents with water to facilitate their applications. Food Chem 187:14-19

Delidovich I, Hausoul PJC, Deng L, Pfutzenreuter R, Rose M, Palkovits R (2016) Alternative monomers based on lignocellulose and their use for polymer production. Chem Rev 116:1540-1599

Dhiman SS, Haw J, Kalyani D, Kalia VC, Kang YC, Lee J (2015) Simultaneous pretreatment and saccharification: green technology for enhanced sugar yields from biomass using a fungal consortium. Bioresour Technol 179:50-57

Digman MF, Shinners KJ, Casler MD (2010) Optimizing on-farm pretreatment of perennial grasses for fuel ethanol production. Bioresour Technol 101:5305-5314

Du W, Yu H, Song L, Zhang J, Weng C, Ma F, Zhang X (2011) The promising effects of by-products from Irpex lacteus on subsequent enzymatic hydrolysis of bio-pretreated corn stalks. Biotechnol Biofuels 4:37

Fan LT, Gharpuray MM, Lee YH (1987) Cellulose hydrolysis biotechnology monographs. Springer, Berlin, p 57

Geng A, Xin F, Ip JY (2012) Ethanol production from horticultural waste treated by a modified organosolv method. Bioresour Technol 104:715-721

Gogate PR, Sutkar VS, Pandit AB (2011) Sonochemical reactors: important design and scale up considerations with a special emphasis on heterogeneous systems. Chem Eng J 166:1066-1082

Grous WR, Converse AO, Grethlein HE (1986) Effect of steam explosion pretreatment on pore size and enzymatic hydrolysis of poplar. Enzyme Microb Technol 8:274-280

Hammel KE, Kapich AN, Jensen KA, Ryan ZC (2002) Reactive oxygen species as agents of wood decay by fungi. Enz Microb Technol 30:445-453

Hendricks AT, Zeeman G (2009) Pretreatments to enhance the digestibility of lignocellulosic biomass. Bioresour Technol 100:10-18

Hideno A, Inoue H, Tsukahara K, Fujimoto S, Minowa T, Inoue S, Endo T, Sawayama S (2009) Wet disk milling pretreatment without sulfuric acid for enzymatic hydrolysis of rice straw. Bioresour Technol 100:2706-2711

Hideno A, Kawashima A, Endo T, Honda K, Morita M (2013) Ethanol-based organosolv treatment with trace hydrochloric acid improves the enzymatic digestibility of Japanese cypress (Chamaecyparis obtusa) by exposing nanofibers on the surface. Bioresour Technol 18:64-70

Hu ZH, Wen ZY (2008) Enhancing enzymatic digestibility of switchgrass by microwave-assisted alkali pretreatment. Biochem Eng J 38:369-378

Huijgen WJJ, Van der Laan RR, Reith JH (2008) Modified organosolv as a fractionation process of lignocellulosic biomass for coproduction of fuels and chemicals. In: Proceedings of the 16th European biomass conference and exhibition, Valencia

Ibrahim MM, El-Zawawy WK, Abdel-Fattah YR, Soliman NA, Agblevor FA (2011) Comparison of alkaline pulping with steam explosion for glucose production from rice straw. Carbohydr Polym 83:720-726

Ichwan M, Son TW (2011) Study on organosolv pulping methods of oil palm biomass. In: International seminar on chemistry. pp 364-370

Idrees M, Adnan A, Qureshi FA (2013) Optimization of sulfide/sulfite pretreatment of lignocellulosic biomass for lactic acid production. BioMed Research International 2013:1-11

Jacquet N, Vanderghem C, Danthine S, Quiévy N, Blecker C, Devaux J, Paquot M (2012) Influence of steam explosion on physicochemical properties and hydrolysis rate of pure cellulose fibers. Bioresour Technol 121:221-227
Jagmann N, Philipp B (2014) Design of synthetic microbial communities for biotechnological production processes. J Biotechnol 184:209-218

Kang S, Li X, Fan J, Chang J (2013) Hydrothermal conversion of lignin: a review. Renew Sust Ener Rev 27:546-558

Karunanithy C, Muthukumarappan K (2010) Influence of extruder temperature and screw speed on pretreatment of corn stover while varying enzymes and their ratios. Appl Biochem Biotechnol 162:264-279

Karunanithy C, Muthukumarappan K, Gibbons WR (2013) Effect of extruder screw speed, temperature, and enzyme levels on sugar recovery from different biomasses. ISRN Biotechnol 942810:1-13

Karunanithy C, Muthukumarappan K, Julson JL (2008) Influence of high shear bioreactor parameters on carbohydrate release from different biomasses. American Society of Agricultural and Biological Engineers, Annual International Meeting 2008. ASABE 084114. ASABE, St. Joseph

Karunanithy V, Muthukumarappan K (2011) Optimizing extrusion pretreatment and big bluestem parameters for enzymatic hydrolysis to produce biofuel using response surface methodology. Int J Agric Biol Eng 4:61-74

Keshwani DR, Cheng JJ (2010) Microwave-based alkali pretreatment of switchgrass and coastal bermudagrass for bioethanol production. Biotechnol Prog 3:644-652

Kilzer FJ, Broido A (1965) Speculations on the nature of cellulose pyrolysis. Pyrodynamics 2:151-163

Kim HJ, Chang JH, Jeong BY, Lee JH (2013) Comparison of milling modes as a pretreatment method for cellulosic biofuel production. J Clean Energy Technol 1:45-48

Kim HK, Hong J (2001) Supercritical $\mathrm{CO}_{2}$ pretreatment of lignocellulose enhances enzymatic cellulose hydrolysis. Bioresour Technol 77:139-144

Kim JS, Kim H, Lee JS, Lee JP, Park SC (2008) Pretreatment characteristics of waste oak wood by ammonia percolation. Appl Biochem Biotechnol 148:15-22

Kim JW, Kim KS, Lee JS, Park SM, Cho HY, Park JC, Kim JS (2011a) Two-stage pretreatment of rice straw using aqueous ammonia and dilute acid Bioresour Technol 102:8992-8999

Kim TH, Lee YY (2005a) Pretreatment and fractionation of corn stover by soaking in aqueous ammonia. Appl Biochem Biotechnol 121:1119-1131

Kim TH, Lee YY (2005b) Pretreatment of corn stover by ammonia recycle percolation process. Bioresour Technol 96:2007-2013

Kim Y, Yu A, Han M, Choi GW, Chung B (2011 b) Enhanced enzymatic saccharification of barley straw pretreated by ethanosolv technology. Appl Biochem Biotechnol 163:143-152

Kleinert M, Barth T (2008) Phenols from lignin. Chem Eng Technol 31:736-745

Koo BW, Min BC, Gwak KS (2012) Structural changes in lignin during organosolv pretreatment of Liriodendron tulipifera and the effect on enzymatic hydrolysis. Biomass Bioenerg 42:24-32

Kootstra AM, Beeftink HH, Scott EL, Sanders JPM (2009) Comparison of dilute mineral and organic acid pretreatment for enzymatic hydrolysis of wheat straw. Biochem Eng J 46:126-131

Kumar AK, Parikh BS, Pravakar M (2016) Natural deep eutectic solvent mediated pretreatment of rice straw: bioanalytical characterization of lignin extract and enzymatic hydrolysis of pretreated biomass residue. Environ Sci Pollut Res Int 23:9265-9275

Kumar P, Barrett DM, Delwiche MJ, Stroeve P (2009) Methods for pretreatment of lignocellulosic biomass for efficient hydrolysis and biofuel production. Ind Eng Chem Res 48:3713-3729

Kumar P, Barrett DM, Delwiche MJ, Stroeve P (2011) Pulsed electric field pretreatment of switchgrass and woodchips species for biofuels production. Ind Eng Chem Res 50:10996-11001

Kumar R, Wyman CE (2009) Effects of cellulase and xylanase enzymes on the deconstruction of solids from pretreatment of poplar by leading technologies. Biotechnol Prog 25:302-314

Kuo CH, Lee CK (2009) Enhanced enzymatic hydrolysis of sugarcane bagasse by $\mathrm{N}$ methylmorpholine-N-oxide pretreatment. Bioresour Technol 100:866-871

Lamsal B, Yoo J, Brijwani K, Alavi S (2010) Extrusion as a thermo-mechanical pre-treatment for lignocellulosic ethanol. Biomass Bioenerg 34:1703-1710

Laser M, Larson E, Dale B, Wang M, Greene N, Lynd LR (2009) Comparative analysis of efficiency, environmental impact, and process economics for mature biomass refining scenarios. Biofpr 3:247-270

Lee J, Houtman CJ, Kim HY, Choi IG, Jeffries TW (2011) Scale-up study of oxalic acid pretreatment of agricultural lignocellulosic biomass for the production of bioethanol. Bioresour Technol 102:7451-7456 
Lee J, Jeffries TW (2011) Efficiencies of acid catalysts in the hydrolysis of lignocellulosic biomass over a range of combined severity factors. Bioresour Technol 102:5884-5890

Lee JW, Rodrigues RCLB, Jeffries TW (2009) Simultaneous saccharification and ethanol fermentation of oxalic acid pretreated corncob assessed with response surface methodology. Bioresour Technol 100:6307-6311

Li L, Yu ST, Liu FS, Xie CS, Xu CZ (2011) Efficient enzymatic in situ saccharification of cellulose in aqueous-ionic liquid media by microwave treatment. BioResources 6:4494-4504

Lin Z, Huang H, Zhang H, Zhang L, Yan L, Chen J (2010) Ball milling pretreatment of corn stover for enhancing the efficiency of enzymatic hydrolysis. Appl Biochem Biotechnol 162:1872-1880

Liu LY, Chen HZ (2006) Enzymatic hydrolysis of cellulose materials treated with ionic liquid [BMIM] Cl. Chin Sci Bull 51:2432-2436

Lu X, Xi B, Zhang Y, Angelidaki I (2011) Microwave pretreatment of rape straw for bioethanol production: focus on energy efficiency. Bioresour Technol 102:7937-7940

Lu Y, Mosier NS (2007) Biomimetic catalysis for hemicelluloses hydrolysis in corn stover. Biotechnol Progr 23:116-123

Lucas M, Hanson SK, Wagner GL, Kimball DB, Rector KD (2012) Evidence for room temperature delignification of wood using hydrogen peroxide and manganese acetate as a catalyst. Bioresour Techno 119:174-180

Luengo E, Martínez JM, Coustets M, Álvarez I, Teissié J, Rols MP, Raso J (2015) A comparative study on the effects of millisecond and microsecond-pulsed electric field treatments on the permeabilization and extraction of pigments from Chlorella vulgaris. J Membrane Biol 248:883-891

Lynd LR, Elander RT, Wyman CE (1996) Likely features and costs of mature biomass ethanol technology. App Biochem Biotechnol 57:741-761

Ma F, Yang N, Xu C, Yu H, Wu J, Zhang X (2010) Combination of biological pretreatment with mild acid pretreatment for enzymatic hydrolysis and ethanol production from water hyacinth. Bioresour Technol 101:9600-9604

Ma R, Xu Y, Zhang X (2015) Catalytic oxidation of biorefinery lignin to valueadded chemicals to support sustainable biofuel production. Chem Sus Chem 8:24-51

Marzialetti T, Olarte MBV, Sievers C, Hoskins TJC, Agrawal PK, Jones CW (2008) Dilute acid hydrolysis of loblolly pine: a comprehensive approach. Ind Eng Chem Res 47:7131-7140

McIntosh S, Vancov T (2010) Enhanced enzyme saccharification of Sorghum bicolor straw using dilute alkali pretreatment. Bioresour Technol 101:6718-6727

Mesa L, González E, Cara C, González M, Castro E, Mussatto SI (2011) The effect of organosolv pretreatment variables on enzymatic hydrolysis of sugarcane bagasse. Chem Eng J 168:1157-1162

Montalbo LM, Johnson L, Khanal SK, Leeuwene JV, Grewell D (2010) Sonication of sugary-2 corn: a potential pretreatment to enhance sugar release. Bioresour Technol 101:351-358

Mosier N, Wyman CE, Dale BE, Elander R, Lee YY, Holtzapple MT, Ladisch M (2005) Features of promising technologies for pretreatment of lignocellulosic biomass. Bioresour Technol 96:673-686

Mosier NS, Ladisch CM, Ladisch MR (2002) Characterization of acid catalytic domains for cellulose hydrolysis and glucose degradation. Biotechnol Bioeng 79(6):610-618

Moultrop JS, Swatloski RP, Moyna G, Rogers RD (2005) High resolution 13-C NMR studies of cellulose and cellulose oligomers in ionic liquid solutions. Chem Commun 2005:1557-1559

Nakamura Y, Daidai M, Kobayashi F (2004) Ozonolysis mechanism of lignin model compounds and microbial treatment of organic acids produced. Water Sci Technol 50:167-172

Neely WC (1984) Factors affecting the pretreatment of biomass with gaseous ozone. Biotechnol Bioeng 26:59-65

Ni M, Leung DYC, Leung MKH, Sumathy K (2006) An overview of hydrogen production from biomass. Fuel Process Technol 87:461-472

Nomanbhay SM, Hussain R, Palanisamy K (2013) Microwave assisted enzymatic saccharification of oil palm empty fruit bunch fiber for enhanced fermentable sugar yield. J Sustain Bioenergy Syst 3:7-17

Ogura M, Phaiboonsilpa N, Yamauchi K, Saka S (2013) Two-step decomposition behavior of rice straw as treated by semi-flow hot-compressed water (in Japanese). J Jpn Inst Energy 92:456
Paiva A, Craveir R, Aroso I, Martins M, Reis RL, Duarte ARC (2014) Natural deep eutectic solvents-solvents for the 21st century. ACS Sustain Chem Eng 2:1063-1071

Panagiotopoulos IA, Chandra RP, Saddler JN (2012) A two-stage pretreatment approach to maximise sugar yield and enhance reactive lignin recovery from poplar wood chips. Bioresour Technol 130:570-577

Park JY, Shiroma R, Al-Haq MI, Zhang Y, Ike M, Arai-Sanoh Y, Ida A, Kondo M, Tokuyasu K (2010a) A novel lime pretreatment for subsequent bioethanol production from rice straw - calcium capturing by carbonation (CaCCO) process. Bioresour Technol 101:6805-6811

Park N, Kim HY, Koo BW, Yeo H, Choi IG (2010b) Organosolv pretreatment with various catalysts for enhancing enzymatic hydrolysis of pitch pine (Pinus rigida). Bioresour Technol 101:7046-7053

Phaiboonsilpa N (2010) Chemical conversion of lignocellulosics as treated by two step semi-flow hot-compressed water. In: Graduate School of Energy Science, Doctoral dissertation, Kyoto University, Kyoto

Potumarthi R, Baadhe RR, Nayak P, Jetty A (2013) Simultaneous pretreatment and saccharification of rice husk by Phanerochete chrysosporium for improved production of reducing sugars. Bioresour Technol 128:113-117

Prado R, Erdocia X, Serrano L, Labidi J (2012) Lignin purification with green solvents. Cellul Chem Technol 46:221-225

Putro JN, Soetaredjo FE, Lin SY, Ju YH, Ismadi S (2016) Pretreatment and conversion of lignocellulose biomass into valuable chemicals. RSC Adv 6:46834-46852

Quesada J, Rubio M, Gomez D (1999) Ozonation of lignin rich solid fractions from corn stalks. J Wood Chem Technol 19:115-137

Rabemanolontsoa H, Saka S (2016) Various pretreatments of lignocellulosics. Bioresour Technol 199:83-91

Rehman MSU, Kim I, Chisti Y, Han JI (2013) Use of ultrasound in the production of bioethanol from lignocellulosic biomass. EEST Part A Energy Sci Res 30:1391-1410

Roberts VM, Stein V, Reiner T, Lemonidou A, Li X, Lercher JA (2011) Towards quantitative catalytic lignin depolymerization. Chem Eur J 17:5939-5948

Romero A, Alonso A, Sastre A, Marquez AN (2016) Conversion of biomass into sorbitol: cellulose hydrolysis on MCM-48 and D-Glucose hydrogenation on Ru/MCM-48. Micropor Mesopor Mat 224:1-8

Saha BC, Cotta MA (2007) Enzymatic saccharification and fermentation of alkaline peroxide pretreated rice hulls to ethanol. Enzyme Microb Technol 41:528-532

Saha BC, Iten BL, Cotta M, Wu YV (2005) Dilute acid pretreatment, enzymatic saccharification, and fermentation of rice hulls to ethanol. Biotechnol Prog 21:3816-3822

Salerno MB, Lee HS, Parameswaran P, Rittmann BE (2009) Using a pulsed electric field as a pretreatment for improved biosolids digestion and methanogenesis. Water Environment Federation WEFTEC. 2005-2018

Sánchez C (2009) Lignocellulosic residues: biodegradation and bioconversion by fungi. Biotechnol Adv 27:185-194

Sant'Ana daSilva A, Inoue H, Endo T, Yano S, Bon EPS (2010) Milling pretreatment of sugarcane bagasse and straw for enzymatic hydrolysis and ethanol fermentation. Biores Technol 101:7402-7409

Sarkar N, Ghosh SK, Bannerjee S, Aikat K (2012) Bioethanol production from agricultural wastes: an overview. Renew Energy 37:19-27

Sassner P, Martensson CG, Galbe M, Zacchi G (2008) Steam pretreatment of $\mathrm{H}_{2} \mathrm{SO}_{4}$ impregnated salix for the production of bioethanol. Biores Technol 99:137-145

Sawada T, Nakmura Y, Kobayashi F, Kuwahara M, Watanabe T (1995) Effects of fungal pretreatment and steam explosion pretreatment on enzymatic saccharification of plant biomass. Biotechnol Bioeng 48:719-724

Shafizadeh F, Bradbury AGW (1979) Thermal degradation of cellulose in air and nitrogen at low temperatures. J Appl Poly Sci 23:1431-1442

Shi J, Chinn MS, Sharma-Shivappa RR (2008) Microbial pretreatment of cotton stalks by solid state cultivation of Phanerochaete chrysosporium. Bioresour Technol 99:6556-6564

Shuai L, Yang Q, Zhu JY, Lu FC, Weimer PJ, Ralph J, Pan XJ (2010) Comparative study of SPORL and dilute-acid pretreatments of spruce for cellulosic ethanol production. Biores Technol 101:3106-3114

Sills DL, Gossett JM (2011) Assessment of commercial hemicellulases for saccharification of alkaline pretreated perennial biomass. Biores Technol 102:1389-1398 
Sindhu R, Binod P, Pandey A (2016) Biological pretreatment of lignocellulosic biomass - an overview. Bioresour Technol 199:76-82

Sivagurunathan P, Kumar G, Bakonyi P, Kim SH, Kobayashi T, Xu KQ, Lakner G, Toth G, Nemestothy N, Bako KB (2016) A critical review on issues and overcoming strategies for the enhancement of dark fermentative hydrogen production in continuous systems. Int J Hydrogen Energy 41:3820-3836

Smith EL, Abbott AP, Ryder KS (2014) Deep eutectic solvents (DESs) and Their applications. Chem Rev 114:11060-11082

Song L, Yu H, Ma F, Zhang X (2013) Biological pretreatment under non-sterile conditions for enzymatic hydrolysis of corn stover. BioResources 8:3802-3816

Suhara H, Kodama S, Kamei I, Maekawa N, Meguro S (2012) Screening of selective lignin-degrading basidiomycetes and biological pretreatment for enzymatic hydrolysis of bamboo culms. Int Biodeter Biodegr 75:176-180

Sun R, Lawther JM, Banks WB (1995) Influence of alkaline pre-treatments on the cell wall components of wheat straw. Industrial Crop Prod 2:127-145

Sun RC, Tomkinson J (2002) Comparative study of lignins isolated by alkali and ultrasound-assisted alkali extractions from wheat straw. Ultrason Sonochem 9:85-93

Sun Y, Cheng J (2002) Hydrolysis of lignocellulosic materials for ethanol production: a review. Bioresour Technol 83:1-11

Sun YE, Cheng JJ (2005) Dilute acid pretreatment of rye straw and Bermuda grass for ethanol production. Bioresour Technol 96:1599-1606

Szijártó N, Kádár Z, Varga E, Thomsen AB, Costa-Ferreira M, Réczey K (2009) Pretreatment of reed by wet oxidation and subsequent utilization of the pretreated fibers for ethanol production. Appl Biochem Biotechnol 155:386-396

Taha M, Shahsavari E, Al-Hothaly K, Mouradov A, Smith AT, Ball AS, Adetutu EM (2015) Enhanced biological straw saccharification through co-culturing of lignocellulose degrading microorganisms. Appl Biochem Biotechnol 175:3709-3728

Taherzadeh MJ, Karimi K (2008) Pretreatment of lignocellulosic wastes to improve ethanol and biogas production: a review. Int J Mol Sci 9:1621-1651

Tang J, Chen K, Huang F, Xu J, Li J (2013) Characterization of the pretreatment liquor of biomass from the perennial grass, Eulaliopsis binata, for the production of dissolving pulp. Bioresour Technol 129:548-552

Uppugundla N, Da Costa Sousa L, Chundawat SPS, Yu X, Simmons B, Singh S, Gao X, Kumar R, Wyman CE, Dale BE, Balan V (2014) A comparative study of ethanol production using dilute acid, ionic liquid and AFEXTM pretreated corn stover. Biotechnol Biofuel 7:72-85

Varga E, Schmidt AS, Réczey K, Thomsen AB (2003) Pretreatment of corn stover using wet oxidation to enhance enzymatic digestibility. Appl Biochem Biotechnol 104:37-50

Vats S, Maurya DP, Shaimoon M, Negi S (2013) Development of a microbial consortium for the production of blend enzymes for the hydrolysis of agricultural waste into sugars. J Sci Ind Res 72:585-590

Vidal PF, Molinier J (1988) Ozonolysis of lignin-improvement of in vitro digestibility of poplar sawdust. Biomass 16:1-17

Villaverde JJ, Ligero P, De Vega A (2010) Miscanthus x giganteus as a source of biobased products through organosolv fractionation: a mini review. Open Agric J 4:102-110

Wan C, LiY (2011) Effectiveness of microbial pretreatment by Ceriporiopsis subvermispora on different biomass feed stocks. Bioresour Technol 102:7507-7512

Wang L, Mu G, Tan C, Sun L, Zhou W, Yu P, Yin J, Fu H (2013) Porous graphitic carbon nanosheets derived from cornstalk biomass for advanced supercapacitors. Chem Sus Chem 6:880-889

Wang W, Yuan T, Wang K, Cui B, Dai Y (2012) Combination of biological pretreatment with liquid hot water pretreatment to enhance enzymatic hydrolysis of Populus tomentosa. Bioresour Technol 107:282-286

Wright JD (1988) Ethanol from biomass by enzymatic hydrolysis. Chem Eng Prog 84:62-74

Wyman CE (1999) Biomass ethanol: technical progress, opportunities, and commercial challenges. Ann Rev Energy Environ 24:189-226

Xu H, Li B, Mu X (2016) Review of alkali-based pretreatment to enhance enzymatic saccharification for lignocellulosic biomass conversion. Ind Eng Chem Res 55:8691-8705

Xu J, Chen H, Kadar Z, Thomsen AB, Schmidt JE, Peng H (2011) Optimization of microwave pretreatment on wheat straw for ethanol production. Biomass Bioenerg 35:385-386
Xu J, Thomsen MH, Thomsen AB (2009) Pretreatment on corn stover with low concentration of formic acid. J Microbiol Biotechnol 19:845-850

Yachmenev V, Condon B, Klasson T, Lambert A (2009) Acceleration of the enzymatic hydrolysis of corn stover and sugar cane bagasse celluloses by low intensity uniform ultrasound. J Biobased Mater Bioenergy 3:25-31

Yang B, Wyman CE (2004) Effect of xylan and lignin removal by batch and flow through pretreatment on enzymatic digestibility of corn stover cellulose. Biotechnol Bioeng 86:88-95

Yang J, Christiansen K, Luchner S (2013) Renewable, low-cost carbon fiber for light weight vehicles. Detroit, U.S. Department of Energy

Yoo JY (2011) Technical and economical assessment of thermo-mechanical extrusion pretreatment for cellulosic ethanol production. Ph.D. Thesis, Kansas State University, Manhattan

Yoshikawa T, Yagi T, Shinohara S, Fukunaga T, Nakasaka Y, Tago T, Masuda T (2013) Production of phenols from lignin via depolymerization and catalytic cracking. Fuel Process Technol 108:69-75

Yu J, Zhang J, He J, Liu Z, Yu Z (2009) Combinations of mild physical or chemical pretreatment with biological pretreatment for enzymatic hydrolysis of rice hull. Bioresour Technol 100:903-908

Yu X, Gouyo T, Grimi N, Bals O, Vorobiev E (2016) Pulsed electric field pretreatment of rapeseed green biomass (stems) to enhance pressing and extractives recovery. Bioresour Technol 199:194-201

Zakaria MR, Fujimoto S, Hirata S, Hassan MA (2014) Ball milling pretreatment of oil palm biomass for enhancing enzymatic hydrolysis. Appl Biochem Biotechnol 173:1778-1789

Zavrel M, Bross D, Funke M, Buchs J, Spiess AC (2009) High-throughput screening for ionic liquids dissolving (ligno-)cellulose. Bioresour Technol 100:2580-2587

Zhang DS, Yang Q, Zhu JY, Pan XJ (2013) Sulfite (SPORL) pretreatment of switchgrass for enzymatic saccharification. Bioresour Technol 129:127-134

Zhang SH, Xu YX, Hanna MA (2012a) Pretreatment of corn stover with twinscrew extrusion followed by enzymatic saccharification. Appl Biochem Biotechnol 166:458-469

Zhang Q, De Vigier KO, Royer S, Jérôme F (2012b) Deep eutectic solvents: syntheses, properties and applications. Chem Soc Rev 41:7108-7146

Zhao X, Liu D (2012) Fractionating pretreatment of sugarcane bagasse by aqueous formic acid with direct recycle of spent liquor to increase cellulose digestibility-the Formiline process. Bioresour Technol 117:25-32

Zhao Y, Wang Y, Zhu JY, Ragauskas A, Deng Y (2008) Enhanced enzymatic hydrolysis of spruce by alkaline pretreatment at low temperature. Biotechnol Bioeng 99:1320-1328

Zheng J, Rehmann L (2014) Extrusion pretreatment of lignocellulosic biomass: a review. Int J Mol Sci 15:18967-18984

Zheng YZ, Lin HM, Tsao GT (1995) Supercritical carbon-dioxide explosion as a pretreatment for cellulose hydrolysis. Biotechnol Lett 17:845-850

Zhu J, Rezende CA, Simister R, McQueen-Mason SJ, Macquarrie DJ, Polikarpov I, Gomez LD (2016) Efficient sugar production from sugarcane bagasse by microwave assisted acid and alkali pretreatment. Biomass Bioenerg 93:269-278

Zhu J, Wan C, Li Y (2010) Enhanced solid-state anaerobic digestion of corn stover by alkaline pretreatment. Bioresour Technol 101:7523-7528

Zhu JY, Pan XJ (2010) Woody biomass pretreatment for cellulosic ethanol production technology and energy consumption evaluation. Bioresour Technol 101:4992-5002

Zhu JY, Pan XJ, Wang GS, Gleisner R (2009) Sulfite pretreatment (SPORL) for robust enzymatic saccharification of spruce and red pine. Bioresour Technol 100:2411-2418

Zhu Z, Macquarrie DJ, Simister R, Gomez LD, McQueen-Mason SJ (2015a) Microwave assisted chemical pretreatment of Miscanthus under different temperature regimes. Sustain Chem Process 3:15-27

Zhu Z, Simister R, Bird S, McQueen-Mason SJ, Gomez LD, Macquarrie DJ (2015b) Microwave assisted acid and alkali pretreatment of Miscanthus biomass for biorefineries. AIMS Bioeng 2:449-468

Zhua JY, Wang GS, Pan XJ, Gleisner R (2009) Specific surface to evaluate the efficiencies of milling and pretreatment of wood for enzymatic saccharification. Chem Eng Sci 64:474-485

Zwart RWR, Boerrigter H, Van der Drift A (2006) The impact of biomass pretreatment on the feasibility of overseas biomass conversion to fischertropsch products. Energy Fuels 20:2192-2197 